\title{
Minettes do Stock Monzonítico Glória Norte: evidência de magmatismo ultrapotássico pós-orogênico, com assinatura de subducção, no Sistema Orogênico Sergipano
}

\author{
Minettes of the Glória Norte Monzonic Stock: evidence of post-orogenic ultrapotassic \\ magmatism, with subduction signature, in the Sergipano Orogenic System \\ Milena Prado Fontes ${ }^{1,2}$, Herbet Conceição ${ }^{1,2}$, Maria de Lourdes da Silva Rosa ${ }^{1,2}$, \\ Vinicius Anselmo Carvalho Lisboa ${ }^{2,3}$ \\ ${ }_{1}^{1}$ Programa de Pós-Graduação em Geociências e Análise de Bacias (PGAB), Universidade Federal de Sergipe - UFS, Avenida \\ Marechal Rondon, s/n, Jardim Rosa Elze,Cidade Universitária Professor José Aloísio de Campos, CEP 49100-000 - São \\ Cristóvão, SE, BR (milenapradofontes@gmail.com; herbet@ufs.br; Irosa@ufs.br) \\ ²Laboratório de Petrologia Aplicada à Pesquisa Mineral (LAPA), Universidade Federal de Sergipe - UFS, São Cristóvão, SE, BR \\ (viniciuslisboa1@hotmail.com) \\ ${ }^{3}$ Pós-Graduação em Geologia, Universidade Federal da Bahia - UFBA, Salvador, BA, BR
}

Recebido em 12 de junho de 2017; aceito em 12 de dezembro de 2017

\begin{abstract}
Resumo
Lamprófiros ocorrem como enclaves microgranulares no Stock Monzonítico Glória Norte (SGN) (588 \pm 5 Ma), localizado na parte central do Domínio Macururé, do Sistema Orogênico Sergipano, no estado de Sergipe. Esses enclaves lamprofíricos foram classificados como minettes e ocorrem concentrados em uma área com aproximadamente $1 \mathrm{~km}$ de diâmetro na região sudeste do stock. Os minettes apresentam texturas porfirítica e panidiomórfica, com fenocristais de biotita e matriz com granulação fina. Os minerais máficos presentes, além da biotita, são: diopsídio, augita, hornblenda e titanita. Ortoclásio pertítico, andesina, biotita, carbonato, apatita e zircão também estão presentes na matriz. Os dados dos elementos maiores $\left(\mathrm{K}_{2} \mathrm{O} / \mathrm{Na}_{2} \mathrm{O}>3,6>\% \mathrm{MgO}>8, \mathrm{~K}_{2} \mathrm{O}>3 \%\right.$ ), menores e traços (baixos valores de Ti, $\mathrm{Nb}$, Ta) indicam magmatismo ultrapotássico orogênico. As razões $\mathrm{Th} / \mathrm{Yb}>9,00$ e $0,05<\mathrm{Ta} / \mathrm{Yb}<0,20$ apontam para magma formado por fusão de um manto enriquecido. As informações obtidas neste estudo indicam que magmas básicos ultrapotássicos estiveram presentes durante o período pós-tectônico no Sistema Orogênico Sergipano (SOS).
\end{abstract}

Palavras-chave: Lamprófiro; Monzonitos; Petrografia; Geoquímica.

\begin{abstract}
Lamprophyres occur as microgranular enclaves in the Glória Norte Monzonitic Stock (588 $\pm 5 \mathrm{Ma})$, located in the central part of the Macururé Domain, Sergipano Orogenic System, in the state of Sergipe, Brazil. These lamprophric enclaves were classified as minettes and occur concentrated in an area of approximately $1 \mathrm{~km}$ in diameter in the southeast region of the stock. The minettes have porphyritic, panidiomorphic textures with biotite phenocrystals, and fine granulation matrix. The mafic minerals present, in addition to the biotite, are diopside, augite, hornblende and titanite. Perthitic orthoclase, andesine, biotite, carbonate, apatite and zircon are also present in the matrix. The data of the major $\left(\mathrm{K}_{2} \mathrm{O} / \mathrm{Na}_{2} \mathrm{O}>3,6>\% \mathrm{MgO}>8, \mathrm{~K}_{2} \mathrm{O}>3 \%\right)$, minor and traces elements (low values of $\mathrm{Ti}, \mathrm{Nb}, \mathrm{Ta}$ ) indicate orogenic ultrapotassic magmatism. The ratio $\mathrm{Th} / \mathrm{Yb}>9.00 \mathrm{and}$ $0.05<\mathrm{Ta} / \mathrm{Yb}<0.20$ points to magma formed by melting of an enriched mantle. The information obtained in this study indicates that ultrapotassic basic magmas were present during the post-tectonic period in the Sergipano Orogenic System (SOS).
\end{abstract}

Keyworks: Lamprophyre; Monzonites; Petrography; Geochemistry. 


\section{INTRODUÇÃO}

A presença de importante volume de granitos no Sistema Orogênico Sergipano (SOS) é um aspecto bem descrito na literatura (e.g., Silva Filho et al., 1979; Davison e Santos, 1989; Santos et al., 2001; Teixeira, 2014; Oliveira et al., 2015; Conceição et al., 2016). Estudos recentes e de detalhe em corpos graníticos desse sistema orogênico em Sergipe têm revelado que esse plutonismo é dominado por magmas calcioalcalinos de médio a alto potássio - K (e.g., Lisboa, 2014; Santos, 2016; Mendonça, 2016). Intrusões shoshoníticas no SOS são limitadas a uns poucos corpos nas partes central (Lisboa, 2014) e norte (Santos et al., 1988; Soares, 2016).

Os estudos desenvolvidos por Lisboa (2014), no Stock Monzonítico Glória Norte (SGN), e Conceição et al. (2016), no Stock Glória Sul (SGS), identificaram nessas intrusões a existência de processos de mistura entre magmas básico e ácido, cujos termos básicos correspondem a enclaves lamprofíricos.

Lamprófiros calcioalcalinos são rochas que ocorrem como corpos de pequenas dimensões (e.g., diques, pipes, sills) ou como enclaves em granitos (e.g., Conceição et al., 2016), sienitos (Conceição et al., 1995; Paim et al., 2002); monzonitos (Plá Cid et al., 2012; Lisboa, 2014) ou dioritos (e.g., Prelevic et al., 2004). Essas rochas são caracterizadas por apresentarem texturas porfirítica e panidiomórfica, com abundantes fenocristais de mica ou anfibólio e feldspatos limitados à matriz (e.g., Rock, 1987, 1991; Woolley et al., 1996; Le Maître et al., 1989). A importância dos lamprófiros em terrenos orogênicos advém do fato de eles apresentarem assinatura geoquímica mantélica (e.g., Rock, 1991; Bédard, 1994) e normalmente resultarem de processo de mistura envolvendo magma mantélico (e.g., Prelevic et al., 2004; Carlier et al., 1997; Caroff et al., 2015).

Este trabalho apresenta e discute dados geológicos, petrográficos e geoquímicos dos enclaves lamprofíricos e cumuláticos presentes no SGN e aporta reflexões sobre as implicações da presença de magmas lamprofíricos na parte central do SOS.

\section{CONTEXTO GEOLÓGICO}

O SOS é interpretado como resultado de colisão neoproterozoica entre o Cráton São Francisco, a sul, e o Maciço Pernambuco-Alagoas, a norte (Brito Neves, 1977; D’el Rey Silva, 1999; Bueno et al., 2009). Oliveira et al. (2015) posicionam a colisão brasiliana presente no SOS como ocorrida entre 570 - 590 Ma. Essa colisão expressa-se pelo desenvolvimento de zonas de cisalhamento e importante granitogênese (Santos et al., 2001).

A estrutura do SOS em faixas orientadas NW-SE, com geologia distintas, levou vários pesquisadores (e.g., Santos et al., 1988; Davison e Santos, 1989) a compartimentarem essas faixas em domínios geológicos (Figura 1). O SOS é formado por um conjunto de seis domínios geológicos que fazem contatos tectônicos entre si. As estruturas observadas nas rochas dos diferentes domínios indicam deslocamento de massa de NE-SW (Santos et al., 2001). Eles são, de norte a sul, nomeados de: Canindé, Poço Redondo, Marancó, Macururé, Vaza-Barris e Estância. Os dois últimos domínios são metassedimentares e não apresentam granitogênese (Davison e Santos, 1989).

O Domínio Macururé (Figura 1), no qual se localiza o objeto deste estudo, é essencialmente metapelítico (ardósias, filitos, xistos), com quartzitos, mármores, rochas calciossilicáticas e vulcânicas subordinadas (Silva Filho et al., 1979; Davison e Santos, 1989; Santos et al., 2001; Lobo, 2016). O metamorfismo presente neste domínio varia da fácies xisto verde até fácies anfibolito nas vizinhanças dos granitos (Santos et al., 2001; Lisboa, 2014; Conceição et al., 2016; Lobo, 2016).

Os granitos no Domínio Macururé são de vários tipos petrográficos (e.g., Humphrey e Allard, 1962; Silva Filho et al., 1979; Santos et al., 1988, 2001) e totalizam 60 intrusões (Conceição et al., 2016). Inicialmente, essas intrusões graníticas foram reunidas sob a terminologia de Batólito Glória (Humphrey e Allard, 1962). Posteriormente, os trabalhos de cartografia geológica regional passaram a nomeá-las de granitos do Tipo Glória (e.g., Silva Filho et al., 1979). Na década de 1980, os granitos foram agrupados com relação à deformação regional em pré-tectônicos, sincrônicos, tardios a pós-tectônicos (e.g., Santos et al., 1988, 2001). Teixeira (2014), ao elaborar o novo mapa geológico de Sergipe, integrou as informações disponíveis sobre a granitogênese no SOS, abandonou a utilização da terminologia "tipo" e agrupou os granitos em suítes, seguindo as recomendações da nomenclatura estratigráfica internacional (e.g., Murphy e Salvador, 1999). No Domínio Macururé, Teixeira (2014) reconhece a presença de quatro suítes que foram nomeadas de Glória Xingó 2 (granitos com muscovita, por vezes com turmalina e granada); Glória-Xingó 1 (granitos equigranulares com duas micas); Queimada-Grande (biotita granitos e monzonitos com biotita); e Coronel João Sá (granitos, granodioritos e granitos).

A integração dos dados sobre os granitos do Domínio Macururé, apresentada por Conceição et al. (2016), revelou que essas rochas têm assinatura orogênica e as intrusões foram reunidas em quatro conjuntos:

1. granodiorítico calcioalcalino de alto $\mathrm{K}$;

2. monzonítico shoshonítico;

3. sienogranítico leucocrático calcioalcalino de alto K;

4. granítico calcioalcalino com textura rapakivi.

O SGN é a melhor expressão do magmatismo shoshonítico no Domínio Macururé. 


\section{ASPECTOS GEOLÓGICOS DO STOCK MONZONÍTICO GLÓRIA NORTE}

O SGN é uma intrusão com área de aproximadamente $50 \mathrm{~km}^{2}$ que se localiza na parte central do Domínio Macururé, em Sergipe (Figura 2). A idade de cristalização do SGN é de $588 \pm 5 \mathrm{Ma}\left(\mathrm{U}_{-} \mathrm{Pb}_{\text {zircão }}\right.$ Shrimp; Lisboa, 2014). O SGN trunca as foliações dos metassedimentos do Domínio Macururé, o que revela que a sua colocação é posterior ao pico da deformação regional (Lisboa, 2014).

Os contatos do $\mathrm{SGN}$ com os metassedimentos encaixantes são dificilmente visíveis em campo, todavia o mapeamento em detalhe, realizado por Lisboa (2014), permitiu delimitar a forma desse stock (Figura 2). A presença de abundantes diques de granito nas encaixantes; o aumento da granulação; e o aparecimento de granada, oligoclásio e biotita nos metapelitos; e de hornblenda, zoisita e oligoclásio nas rochas calciossilicáticas refletem o aquecimento provocado pelo SGN e indicam que as condições do metamorfismo de contato nessas áreas atingiram o médio grau (Lisboa, 2014; Lobo, 2016). Essas evidências permitiram a Lisboa (2014) representar uma área de rochas hornfélsicas (Figura 2).

As características marcantes e que distinguem o SGN dos outros granitos do Domínio Macururé, segundo Lisboa (2014), são: textura porfirítica; composição monzonítica; abundância de enclaves máficos microgranulares; e ocorrência de enclaves lamprofíricos e de biotita diopsídio cumulatos. Xenólitos de metassedimentos são raros.

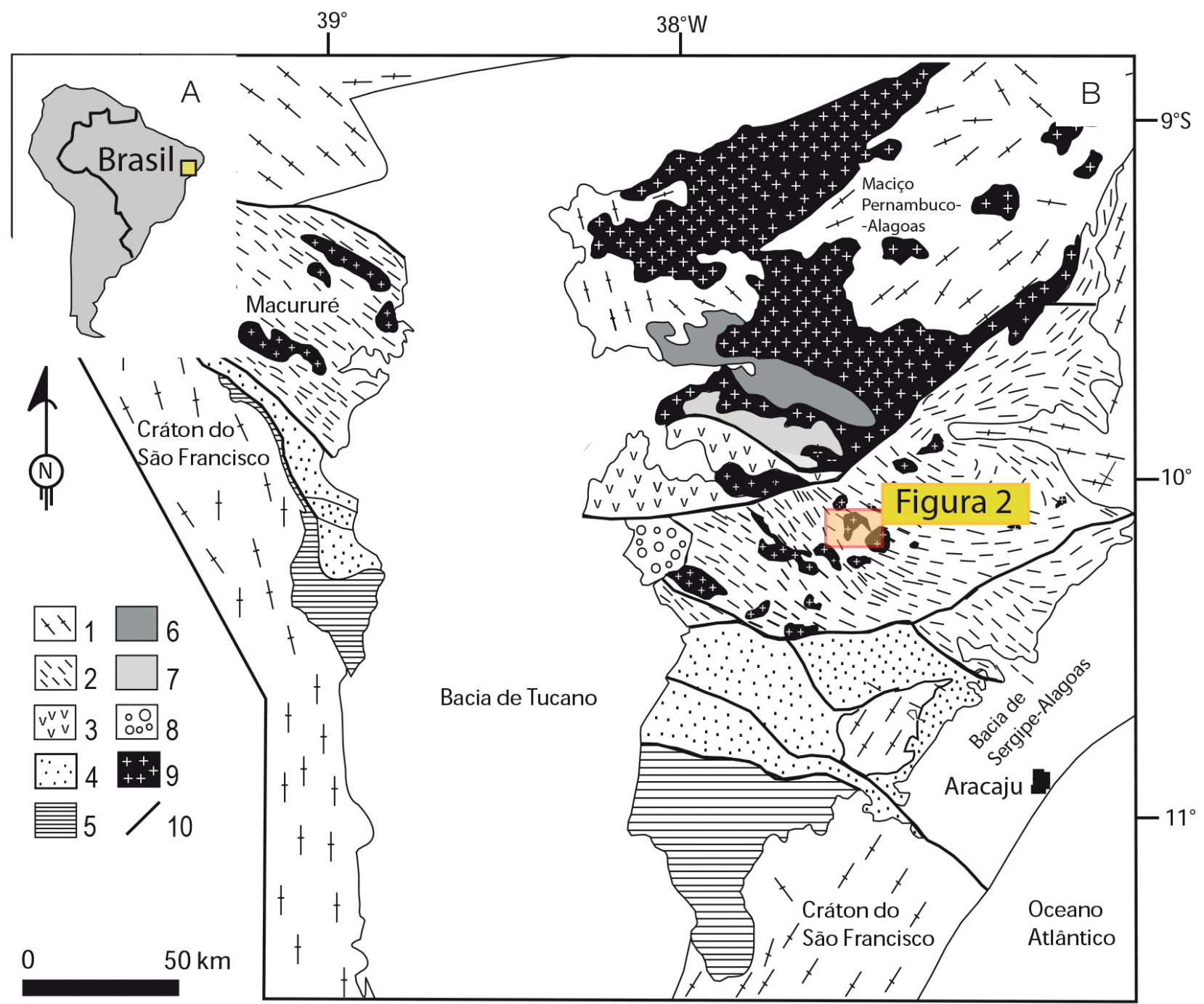

Figura 1. (A) Contorno geográfico da América do Sul e do Brasil, com polígono amarelo localizando a área da Figura B; esquema geológico do Sistema Orogênico Sergipano, apresentando: (B) os domínios geológicos descritos por Davison e Santos (1989). (1) gnaisses de alto grau, (2) Domínio Macururé, (3) Domínio Marancó, (4) Domínio Vaza-Barris, (5) Domínio Estância, (6) Domínio Canindé, (7) Domínio Paço Redondo, (8) Graben Juá, (9) Plutões brasilianos e (10) Zonas de cisalhamento. 
Os enclaves de lamprófiros foram identificados no SGN por Lisboa (2014), que chamou atenção para o fato de esses enclaves concentrarem-se em uma região na parte centro-oeste do stock, com cerca de $1 \mathrm{~km}$ de diâmetro, conhecida como área da Pedreira do Didi (Figura 2).

Os tamanhos dos enclaves lamprofíricos variam de poucos centímetros até $1,3 \mathrm{~m}$ de comprimento (Figura $3 \mathrm{~A}$ ), e essas rochas contêm fenocristais de biotita (Figura 3B). Os contatos entre esses enclaves e os quartzo monzonitos

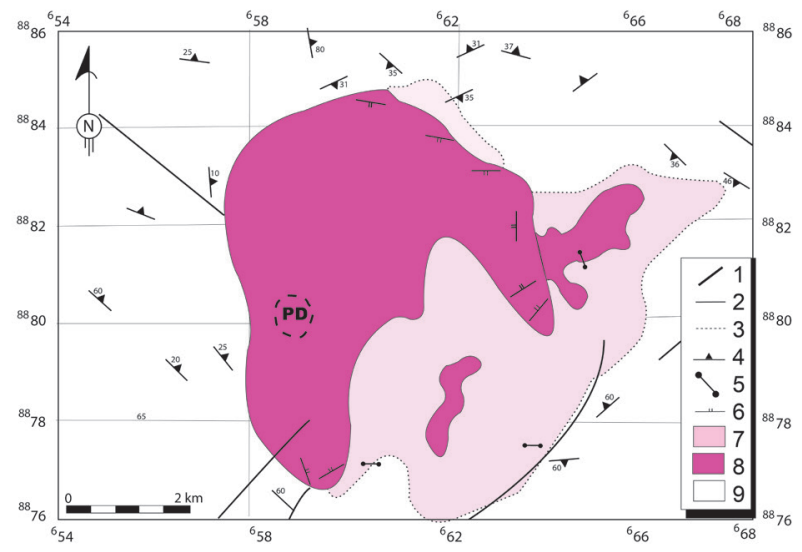

PD: Pedreira do Didi.

Figura 2. Esboço geológico do Stock Monzonítico Glória Norte simplificado de Lisboa (2014). (1) Fratura ou falha, (2) contato inferido, (3) contato gradacional, (4) foliação metamórfica, (5) dique granítico, (6) foliação magmática, (7) região de ocorrência de hornfels, (8) monzonito; área da Pedreira do Didi onde ocorrem os enclaves lamprofíricos; (9) metassedimentos do Domínio Macururé. e monzonitos encaixantes são bem definidos e apresentam geometria curva e ameboide. Contatos similares são interpretados por Barbarin e Didier (1991) como indicativos de coexistência de magmas.

No interior dos enclaves lamprofíricos, e ocasionalmente nos quartzo monzonitos, ocorrem enclaves arredondados, sem orientação, de cor verde oliva e com granulação média, que correspondem à biotita diopsídio cumulatos (Figura 3C). Nos enclaves maiores de lamprófiros, esses cumulatos chegam a ter $14 \mathrm{~cm}$ de diâmetro. Os enclaves de biotita diopsídio cumulatos são ocasionais e apresentam borda de hornblenda bem desenvolvida quando ocorrem nos monzonitos, revelando desequilíbrio químico entre o magma monzonítico e os cumulatos. A borda de hornblenda é ausente quando os biotitas diopsídios cumulatos ocorrem nos lamprófiros, o que sugere equilíbrio químico entre eles. Rock (1991) interpretou a presença de cumulatos clinopiroxeníticos em lamprófiros caledonianos da Escócia, similares aos encontrados no SGN, como produto de acumulação precoce resultante da cristalização fracionada do magma lamprofírico.

\section{AMOSTRAGEM E MÉTODOS ANALÍTICOS}

As seis amostras tratadas neste estudo correspondem a rochas sem alteração, de cor cinza a cinza-escura, que exibem texturas magmáticas. Coletou-se para as análises a parte central dos enclaves (lamprófiro e cumulato) procurando descartar possíveis interações entre os magmas monzonítico e lamprofírico que normalmente tendem a ocorrer na periferia dos enclaves, como as bordas de anfibólio ou biotita. Os xenocristais de feldspatos presentes em alguns
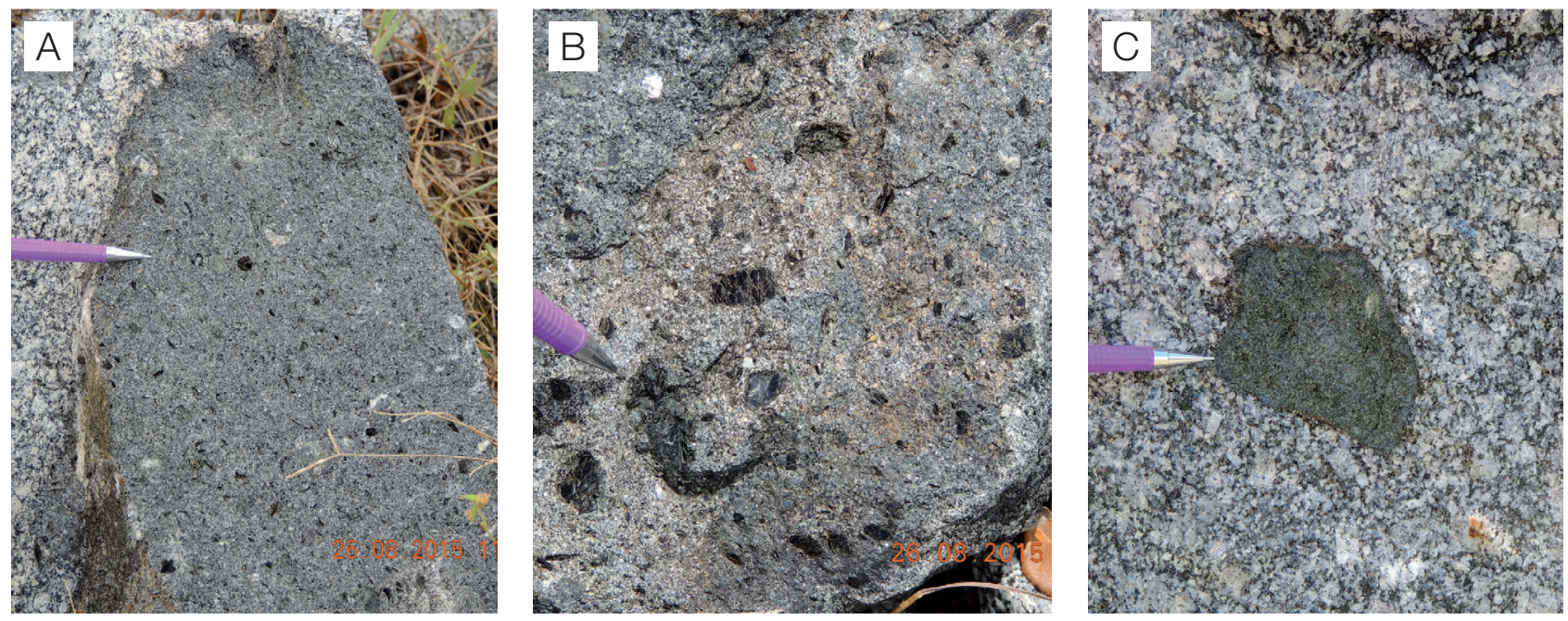

Figura 3. Imagens macroscópicas representativas dos enclaves do Stock Monzonítico Glória Norte; enclave de lamprófiro (cor cinza) com textura porfirítica incluso em monzonito; (A) as pontuações pretas correspondem a cristais de biotita; (B) detalhe dos fenocristais de biotita em matriz fanerítica fina no lamprófiro; (C) enclave de biotita diopsídio cumulato em quartzo monzonito. 
lamprófiros foram extraídos manualmente após a britagem das amostras, de forma a assegurar que os dados químicos obtidos correspondessem à composição mais próxima do magma original lamprofírico.

O estudo microscópico iniciou-se com o microscópio petrográfico- metalográfico. Posteriormente, as lâminas delgado-polidas foram metalizadas com carbono para serem investigadas com auxílio de detector de elétrons retroespalhados em microscópio eletrônico de varredura (MEV) no Laboratório de Microanálise do Condomínio de Laboratórios Multiusuários das Geociências da Universidade Federal de Sergipe (UFS). O MEV utilizado é da marca Tescan ${ }^{\circledast}$, modelo Vega 3 LMU.

A composição química dos cristais de feldspatos e clinopiroxênios foi determinada com um espectrômetro de energia dispersiva, com detector SDD (Silicon Drift Detectors), da marca Oxford Instrumentos ${ }^{\circledR}$, modelo X-act, com poder de resolução $125 \mathrm{eV}$. Utilizou-se o software Quant, da Oxford Instrumentos ${ }^{\circledR}$, para a determinação da composição química pontual dos cristais. O tempo médio de contagem nessas dosagens foi de 60 segundos. A correção utilizada no tratamento dos dados químicos obtidos foi a ZAF. Padrões utilizados foram da Artimex ${ }^{\circledR} \mathrm{e}$ correspondem a cristais de feldspatos e augita. A precisão nos resultados dos elementos químicos variou com a sua concentração, sendo inferior a $2 \%$ para elementos com concentração superior a $10 \%$ em peso, e de até $30 \%$ para elementos químicos com concentrações inferiores a $5 \%$ em peso. As condições analíticas foram de $20 \mathrm{Kv}$ e $17 \mathrm{nA}$, obtendo-se feixe de elétrons com $420 \mathrm{~nm}$ de diâmetro.

As análises químicas foram realizadas na Acme Laboratories (atualmente Bureau Veritas), no Canadá. O pacote analítico foi o Geo3 (Grupos 4A e 4B), que é o recomendado por esse laboratório para estudos petrológicos. Os elementos maiores e menores foram dosados por Inductively
Coupled Plasma Optical Emission Spectrometry (ICP-OES), e os elementos-traço, por Inductively Coupled Plasma Mass Spectrometry (ICP-MS). A precisão foi de $2 \%$.

\section{PETROGRAFIA DOS LAMPRÓFIROS E DO CUMULATO}

Neste estudo foram analisadas cinco amostras representativas de lamprófiros e uma de cumulato ultramáfico (Tabela 1). Para nomear essas rochas seguiu-se as recomendações de Le Maître et al. (1989).

\section{Lamprófiros}

A textura e a mineralogia presentes nos lamprófiros permitem nomeá-los como minettes. Segundo a classificação de Le Maître et al. (1989), minette é um lamprófiro que tem maior abundância de fenocristais de biotita em relação a outros minerais máficos (e.g., hornblenda, diopsídio, augita) e que na matriz tem a predominância de feldspato alcalino ou potássico sobre o plagioclásio. Os minettes estudados alocam-se no diagrama QAP no campo do quartzo sienito (Figura 4).

As diferentes amostras de minettes estudadas mostram texturas e mineralogia similares, sugerindo que esses enclaves que ocorrem distribuídos na área da Pedreira do Didi, no SGN, constituem amostragem representativa do magma básico que invadiu o magma latítico responsável pela cristalização dos monzonitos do SGN.

Os fenocristais de biotita marrom, embora constantes em todos os enclaves observados, não chegam a perfazer 3\% do volume da rocha. Esses cristais são euédricos e subédricos e apresentam tamanhos variando de $5,0 \mathrm{~mm}$ a $4,5 \mathrm{~cm}$. Eles incluem cristais de: minerais opacos anédricos

Tabela 1. Análise modal (\% volume) dos minettes e cumulato do Stock Monzonítico Glória Norte. Cumulato ultramáfico (FDS-77J) e lamprófiros (FDS-3C, FDS-77C, FDS-77E, FDS-77I, FDS-77G).

\begin{tabular}{lcccccc}
\hline Rochas/Minerais & FDS-77J & FDS-3C & FDS-77C & FDS-77E & FDS-77I & FDS-77G \\
\hline Diopsídio & 71,0 & 17,3 & 16,6 & 22,1 & 25,0 & 22,1 \\
Biotita & 26,0 & 37,2 & 29,4 & 40,0 & 25,0 & 34,9 \\
Quartzo & 3,0 & 8,5 & 8,3 & 2,4 & 6,0 & 5,1 \\
Carbonato & $<0,1$ & - & - & - & - & $<0,1$ \\
Minerais opacos & $<0,1$ & 0,2 & $<0,1$ & $<0,1$ & $<0,1$ & $<0,1$ \\
Andesina & - & 10,4 & 9,4 & 4,6 & 9,1 & 10,2 \\
Ortoclásio & - & 22,6 & 31,1 & 24,0 & 30,0 & 23,1 \\
Hornblenda & - & 2,9 & 4,6 & 4,6 & 4,0 & 3,9 \\
Epídoto & - & 0,3 & 0,3 & 0,2 & 0,3 & 0,1 \\
Titanita & - & 0,5 & 0,6 & 0,4 & 0,4 & 0,2 \\
Apatita & $<, 1$ & 0,1 & 0,2 & 1,3 & 0,2 & 0,4 \\
Zircão & - & $<0,1$ & 0,1 & $<0,1$ & $<0,1$ & $<0,1$ \\
& 100,0 & 100,0 & 100,0 & 100,0 & 100,0 & 100,0 \\
\hline
\end{tabular}




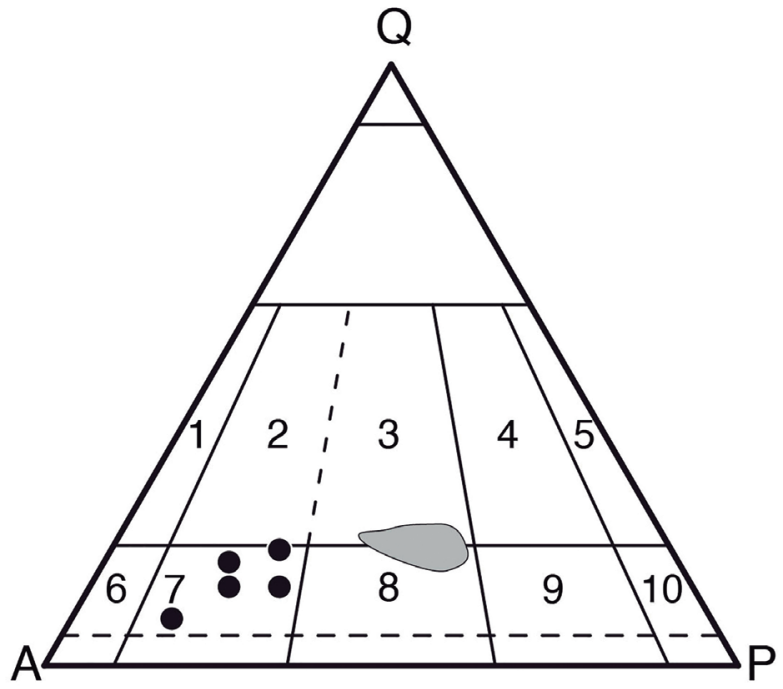

Figura 4. Diagrama modal Q-A-P de Streckeisen (1976) aplicado aos minettes do Stock Monzonítico Glória Norte; (A) feldspato alcalino, (P) plagioclásio e (Q) quartzo; (1) granito alcalino, (2) sienogranito, (3) monzogranito, (4) granodiorito, (5) tonalito/trondhjemito, (6) quartzo sienito alcalino, (7) quartzo sienito, (8) quartzo monzonito, (9) quartzo monzodiorito/ quartzo monzograbro, (10) quartzo diorito/quartzo gabro; a área cinza corresponde à composição das rochas do Stock Glória Norte (Lisboa, 2014).
$(<0,4 \mathrm{~mm})$, diopsídio subédrico/acicular $(<0,2 \mathrm{~mm})$, titanita subédrica $(<0,3 \mathrm{~mm})$, apatita acicular $(<0,2 \mathrm{~mm})$, hornblenda subédrica $(<0,3 \mathrm{~mm})$ e zircão subédrico e euédrico $(<0,2 \mathrm{~mm})$. Usualmente, os minerais opacos ocupam as clivagens e fraturas.

A matriz, de granulação fina, representa cerca de 98\% do volume das rochas (Figura 5A). Essa matriz mesocrática a melanocrática é constituída por biotita, ortoclásio, plagioclásio, diopsídio, hornblenda, minerais opacos, quartzo, apatita, zircão, carbonato, epídoto e allanita.

Os cristais de biotita da matriz apresentam pleocroísmo variando de marrom a marrom-claro. A granulação varia de 0,2 a 0,7 mm, predominando cristais com 0,4 mm (Figura 5A). Eles mostram-se subédricos e esqueléticos (face 001 alongada). Os contatos são retos e curvos com diopsídio e hornblenda. Localmente, esses cristais ocorrem em aglomerados com cristais de hornblenda, diopsídio e minerais opacos. Incluem cristais de apatita acicular (Figura 5B), zircão, titanita, hornblenda e diopsídio subédricos.

O clinopiroxênio apresenta fraco pleocroísmo (incolor a verde claro). Os cristais são subédrico, euédrico e ocasionalmente esquelético, têm granulação variando de 0,1 até $1,0 \mathrm{~mm}$, predominando com $0,5 \mathrm{~mm}$. Vários cristais apresentam-se zonados e a composição dominante é diopsídio (Tabela 2, Figura 6), mas augita pode ocorrer no centro. As análises químicas pontuais obtidas indicam que, embora sutis, as mudanças nas composições químicas de alguns
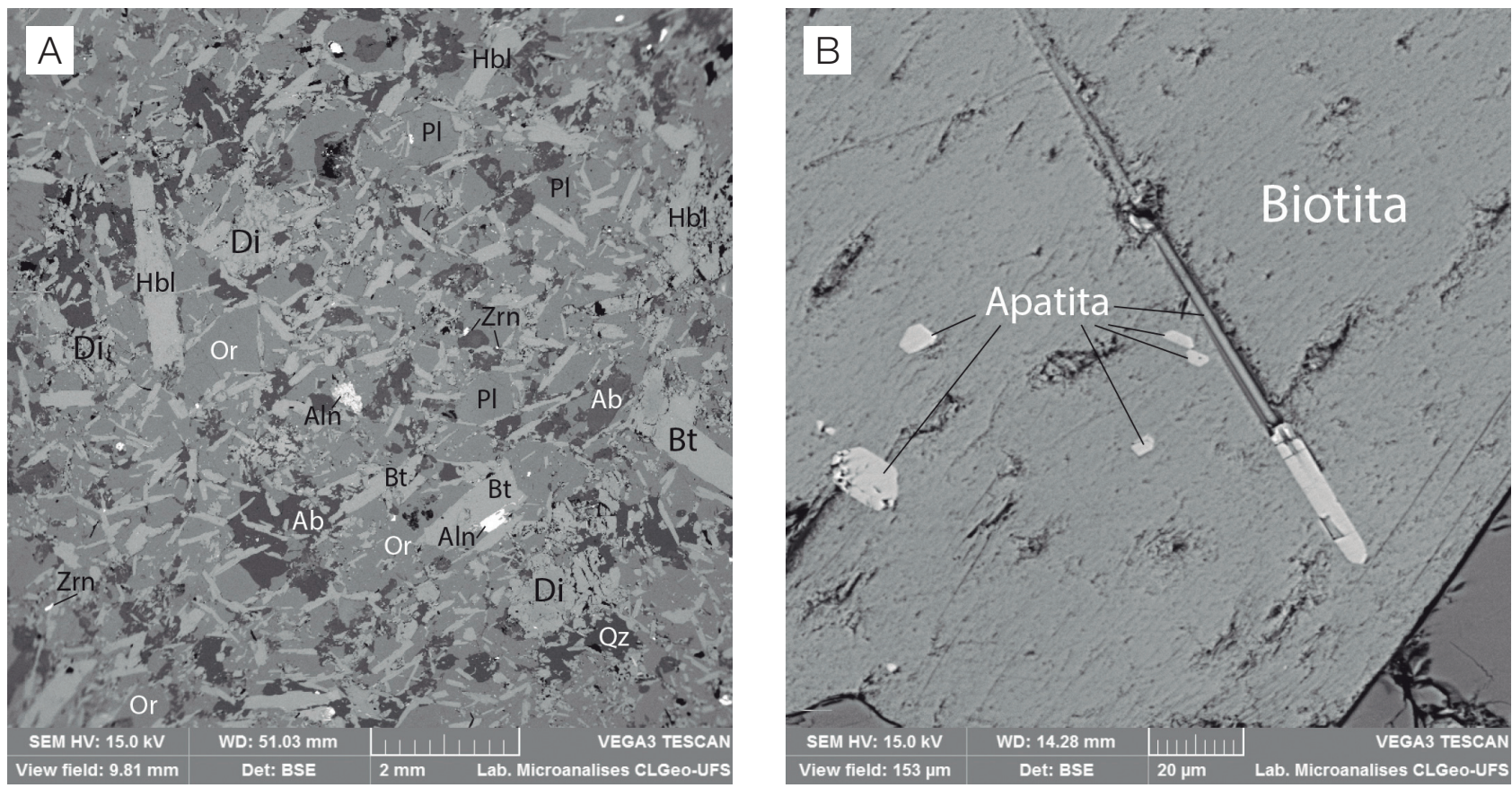

Or: ortoclásio; Hbl: hornblenda; Di: diopsídio; Bt: biotita; Ab: albita; PI: plagioclásio; Zrn: zircão; Aln: allanita; Qz: quartzo; BSE: Backscatered Electrons.

Figura 5. (A) Textura geral da matriz do minette observada com imagem eletrônica de elétrons retroespahados; (B) presença de cristal poiquilítico de biotita da matriz contendo cristais aciculares de apatita. 
cristais são cíclicas (Figura 7A). Em outros, as mudanças das composições químicas são gradacionais (Figura 7B). Os contatos são curvos com a biotita e hornblenda, e retos com os feldspatos. Por vezes, esses cristais são bordejados por cristais de hornblenda verde. Inclui cristais de biotita subédrica, zircão e apatita euédricos. A sua composição química é comparável com a descrita por Rock (1987) para clinopiroxênios de lamprófiros calcioalcalinos.

O feldspato alcalino pertítico ocorre anédrico, ocasionalmente subédrico e com tamanhos entre 0,4 e $0,8 \mathrm{~mm}$. As geminações albita-periclina e Carlsbad são presentes. A extinção ondulante concêntrica ocorre em vários cristais, particularmente naqueles subédricos e indica zoneamento composicional. Inclui biotita, apatita, diopsídio e hornblenda.

Os cristais de plagioclásio correspondem a oligoclásio e andesina (Tabela 3, Figura 8), e a composição albita limita-se à periferia de alguns cristais. Ocorrem subédricos, anédricos e geminados segundo as leis albita e albita-Carlsbad. Exibem com frequência extinção ondulante concêntrica que corresponde à zonação química normal e incluem diopsídio, apatita, zircão e biotita.

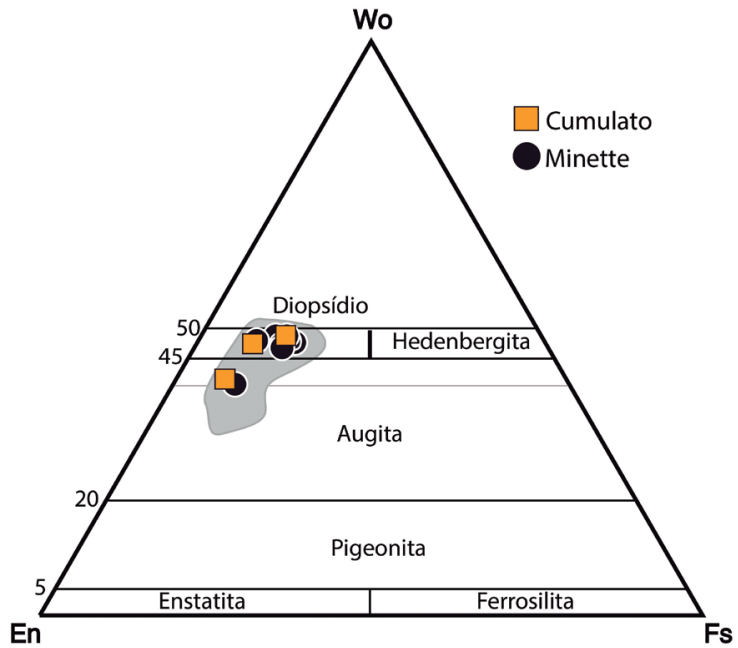

Wo: Wollastonita; En: Enstatita; Fs: Ferrossilita.

Figura 6. Classificação dos clinopiroxênios dos minettes do Stock Monzonítico Glória Norte utilizando o Diagrama Wollastonita-Enstatita-Ferrossilita de Morimoto (1989). A área em cinza corresponde à composição de clinopiroxênios de minettes de Rock (1987).

Tabela 2. Composições representativas de cristais de clinopiroxênio do biotita diopsídio cumulato e minettes do Stock Monzonítico Glória Norte. Fórmula estrutural calculada com base em seis oxigênios.

\begin{tabular}{|c|c|c|c|c|c|c|c|c|c|c|}
\hline & & Biotita o & psídio cl & nulato & & & & Minettes & & \\
\hline & $A$ & A & D & D & D & A & D & D & D & D \\
\hline $\mathrm{SiO}_{2}$ & 54,4 & 54,3 & 53,9 & 53,8 & 54,1 & 54,4 & 53,9 & 54,6 & 53,1 & 53,9 \\
\hline $\mathrm{TiO}_{2}$ & 0,1 & 0,3 & - & - & 0,1 & 0,1 & 0,2 & - & 0,3 & 0,2 \\
\hline $\mathrm{Al}_{2} \mathrm{O}_{3}$ & 1,3 & 0,9 & 1,0 & 0,8 & 1,3 & 1,2 & 1,0 & 1,4 & 1,7 & 1,4 \\
\hline $\mathrm{Cr}_{2} \mathrm{O}_{3}$ & 0,1 & - & - & 0,4 & - & - & - & - & - & - \\
\hline $\mathrm{FeO}$ & 6,6 & 5,0 & 7,4 & 7,9 & 4,3 & 6,3 & 5,6 & 6,1 & 7,0 & 7,3 \\
\hline $\mathrm{MnO}$ & 0,3 & 0,4 & 0,6 & 0,5 & 0,3 & 0,3 & 0,4 & 0,2 & 0,4 & 0,1 \\
\hline $\mathrm{MgO}$ & 16,0 & 15,6 & 13,8 & 13,9 & 16,7 & 15,7 & 15,4 & 16,7 & 15,0 & 15,6 \\
\hline $\mathrm{CaO}$ & 20,3 & 23,3 & 22,9 & 22,9 & 22,6 & 21,6 & 23,0 & 20,5 & 21,9 & 20,9 \\
\hline $\mathrm{Na}_{2} \mathrm{O}$ & 0,6 & 0,3 & 0,4 & 0,2 & 0,2 & 0,3 & 0,4 & - & 0,6 & 0,5 \\
\hline Total & 99,7 & 1,1 & 1,0 & 1,4 & 99,6 & 99,9 & 99,9 & 99,5 & 1,0 & 99,9 \\
\hline $\mathrm{Si}$ & 1,998 & 1,991 & 1,999 & 1,993 & 1,982 & 1,997 & 1,986 & 2,000 & 1,964 & 1,985 \\
\hline $\mathrm{Ti}$ & 0,003 & 0,008 & - & - & 0,003 & 0,003 & 0,006 & - & 0,008 & 0,006 \\
\hline $\mathrm{Al}$ & 0,056 & 0,039 & 0,044 & 0,035 & 0,056 & 0,052 & 0,043 & 0,060 & 0,074 & 0,061 \\
\hline $\mathrm{Cr}$ & 0,003 & - & - & 0,012 & - & - & - & - & - & - \\
\hline $\mathrm{Fe}^{2+}$ & 0,203 & 0,153 & 0,230 & 0,245 & 0,132 & 0,193 & 0,173 & 0,187 & 0,216 & 0,225 \\
\hline $\mathrm{Mn}$ & 0,009 & 0,012 & 0,019 & 0,016 & 0,009 & 0,009 & 0,012 & 0,006 & 0,013 & 0,003 \\
\hline Mg & 0,876 & 0,853 & 0,763 & 0,768 & 0,912 & 0,859 & 0,846 & 0,912 & 0,827 & 0,857 \\
\hline $\mathrm{Ca}$ & 0,799 & 0,915 & 0,910 & 0,909 & 0,887 & 0,850 & 0,908 & 0,805 & 0,868 & 0,825 \\
\hline $\mathrm{Na}$ & 0,043 & 0,021 & 0,029 & 0,014 & 0,014 & 0,021 & 0,029 & - & 0,043 & 0,036 \\
\hline Total & 4,000 & 3,992 & 3,993 & 3,991 & 3,995 & 3,985 & 4,002 & 3,970 & 4,013 & 3,997 \\
\hline$\%$ En & 0,47 & 0,44 & 0,40 & 0,39 & 0,47 & 0,45 & 0,44 & 0,46 & 0,44 & 0,45 \\
\hline$\%$ Fs & 0,11 & 0,09 & 0,13 & 0,14 & 0,08 & 0,10 & 0,09 & 0,14 & 0,10 & 0,12 \\
\hline$\%$ Wo & 0,43 & 0,47 & 0,47 & 0,47 & 0,46 & 0,45 & 0,47 & 0,40 & 0,46 & 0,43 \\
\hline
\end{tabular}

A: augita; D: diopsídio. 
A hornblenda verde é subédrica e anédrica e apresenta tamanhos compreendidos entre 0,2 e $0,9 \mathrm{~mm}$, predominando cristais com $0,4 \mathrm{~mm}$. Ocorre em agregados com cristais de diopsídio, biotita e minerais opacos. Inclui cristais de: diopsídio subédricos
$(<0,3 \mathrm{~mm})$, minerais opacos anédricos e subédricos $(<0,1 \mathrm{~mm})$, vermículas de quartzo $(<0,1 \mathrm{~mm})$ e apatita euédrica $(<0,1 \mathrm{~mm})$.

A titanita ocorre subédrica e anédrica, existindo cristais euédricos ocasionais. Os tamanhos variam de 0,1 a $0,7 \mathrm{~mm}$,
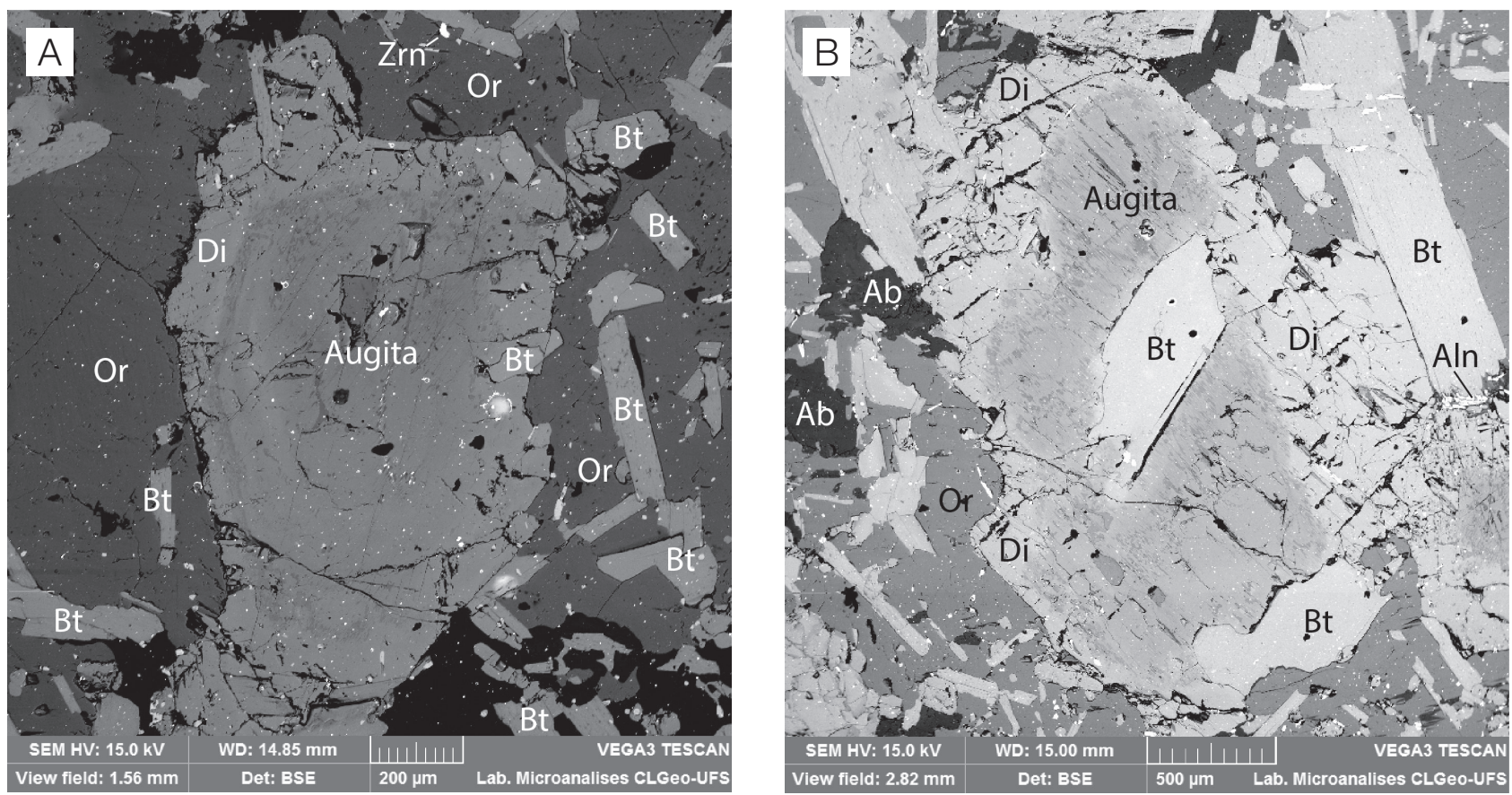

Or: ortoclásio; Di: diopsídio: Bt: biotita; Zrn: zircão; Ab: albita; Aln: allanita; BSE: Backscatered Electrons.

Figura 7. Imagens Backscatered Electrons de cristais clinopiroxênios em minette apresentando zonação composicional; (A) zonação cíclica e (B) zonação gradacional e inclusão de cristal subédrico de biotita.

Tabela 3. Composições representativas de cristais de feldspatos dos minettes estudados do Stock Monzonítico Glória Norte. Fórmula estrutural calculada com base em oito oxigênios.

\begin{tabular}{lccccccccc}
\hline & FDS-3C & FDS-3C & FDS-3C & FDS-77C & FDS-77C & FDS-77I & FDS-77G & FDS-3C & FDS-3C \\
\hline $\mathrm{SiO}_{2}$ & 59,0 & 62,0 & 60,9 & 62,7 & 63,2 & 63,5 & 66,9 & 64,4 & 68,7 \\
$\mathrm{Al}_{2} \mathrm{O}_{3}$ & 25,0 & 24,2 & 24,5 & 23,8 & 23,0 & 23,0 & 20,0 & 18,7 & 19,4 \\
$\mathrm{FeO}$ & - & - & 0,2 & 0,0 & 0,1 & 0,1 & - & 0,1 & - \\
$\mathrm{CaO}$ & 7,9 & 6,2 & 5,9 & 4,4 & 4,2 & 3,9 & 1,6 & 0,1 & 0,3 \\
$\mathrm{Na}_{2} \mathrm{O}$ & 7,4 & 7,8 & 8,3 & 8,8 & 9,1 & 9,5 & 10,7 & 0,7 & 11,5 \\
$\mathrm{~K}_{2} \mathrm{O}$ & 0,1 & 0,2 & 0,2 & 0,2 & 0,3 & 0,1 & 0,1 & 15,7 & 0,0 \\
$\mathrm{BaO}$ & - & - & - & - & - & - & - & 0,3 & - \\
$\mathrm{Total}$ & 99,4 & 1,4 & 1,0 & 99,9 & 99,9 & 1,1 & 99,3 & 1,0 & 99,9 \\
\hline $\mathrm{Si}$ & 2,653 & 2,739 & 2,710 & 2,774 & 2,799 & 2,804 & 2,952 & 2,980 & 3,000 \\
$\mathrm{Al}_{\text {tot }}$ & 1,325 & 1,260 & 1,285 & 1,241 & 1,200 & 1,197 & 1,040 & 1,020 & 0,999 \\
$\mathrm{Fe}^{+3}$ & - & - & 0,007 & - & 0,004 & 0,004 & - & 0,004 & - \\
$\mathrm{Ca}^{+2}$ & 0,381 & 0,293 & 0,281 & 0,209 & 0,199 & 0,184 & 0,076 & 0,005 & 0,014 \\
$\mathrm{Na}^{+}$ & 0,645 & 0,668 & 0,716 & 0,755 & 0,781 & 0,813 & 0,916 & 0,063 & 0,974 \\
$\mathrm{~K}^{+}$ & 0,006 & 0,011 & 0,011 & 0,011 & 0,017 & 0,006 & 0,006 & 0,927 & 0,000 \\
$\mathrm{Ba}^{+2}$ & - & - & - & - & - & - & - & 0,005 & - \\
$\mathrm{Total}$ & 5,010 & 4,971 & 5,011 & 4,989 & 5,000 & 5,007 & 4,989 & 5,004 & 4,987 \\
\hline$\% \mathrm{Or}$ & 0,6 & 1,2 & 1,1 & 1,2 & 1,7 & 0,6 & 0,6 & 93,2 & - \\
$\% \mathrm{Ab}$ & 62,5 & 68,7 & 71,0 & 77,4 & 78,3 & 81,1 & 91,8 & 6,3 & 98,6 \\
$\% \mathrm{An}$ & 36,9 & 30,2 & 27,9 & 21,4 & 20,0 & 18,4 & 7,6 & 0,5 & 1,4 \\
\hline
\end{tabular}


predominando cristais com $0,4 \mathrm{~mm}$. Incluem com frequência minerais opacos.

O epídoto apresenta-se subédrico e euédrico. Os tamanhos variam de 0,2 a $0,5 \mathrm{~mm}$ predominando cristais com $0,2 \mathrm{~mm}$. Inclui cristais anédricos de minerais opacos.

Os cristais de zircão, apatita e allanita apresentam-se euédricos e subédricos, e seus tamanhos não ultrapassam $0,1 \mathrm{~mm}$. Em algumas rochas, os cristais de apatita esqueléticos ocorrem como longas acículas. Os minerais opacos ocorrem subédricos, anédricos e esqueléticos, e correspondem à magnetita, ilmenita e pirita.

\section{Biotita diopsídio cumulato}

Esta rocha apresenta texturas equigranular e allotriomórfica, sendo constituída por diopsídio/augita (Figura 7), biotita, quartzo, minerais opacos, carbonato e apatita.

Os cristais de diopsídio/augita, com tamanho médio de $0,7 \mathrm{~mm}$, são subédricos a anédricos. A composição augita foi identificada no centro de alguns cristais. Os contatos são retos e irregulares com os cristais de biotita, hornblenda e minerais opacos. Nota-se a presença de zonação composional similar àquelas identificadas nos clinopiroxênios dos minettes. É bordejado parcialmente por cristais de hornblenda.

Os cristais biotita apresentam pleocroísmo, variando de marrom a amarelado, são euédricos e subédricos. Os tamanhos situam-se entre 0,2 e $0,7 \mathrm{~mm}$. Ocasionalmente, apresentam-se em aglomerados com cristais de diopsídio e hornblenda.

Quartzo anédrico, com tamanhos entre 0,12 e 0,80 mm, ocorre intersticial. Apatita euédrica, com granulação variando de 0,08 a $0,06 \mathrm{~mm}$, está intimamente associada aos cristais de biotita.

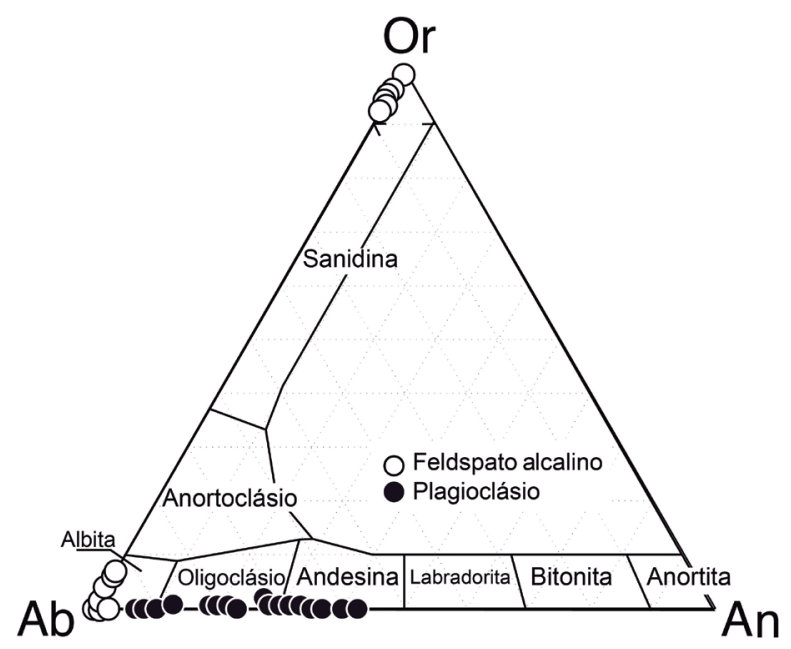

Ab: Albita; An: Anortita; Or: Ortoclásio.

Figura 8. Diagrama Albita-Anortita-Ortoclásio de classificação dos feldspatos aplicado aos minettes do Stock Monzonítico Glória Norte.

\section{GEOQUÍMICA}

As análises químicas foram feitas em seis amostras representativas (Tabela 4). Uma rocha corresponde ao biotita diopsídio cumulato (FDS-77J) e as outras cinco são de minettes.

O conteúdo dos elementos maiores nos minettes estudados apresenta pequena variação (Tabela 4): 55,20 - 56,90\% $\mathrm{SiO}_{2} ; 0,76-0,80 \% \mathrm{TiO}_{2} ; 12,40-12,80 \% \mathrm{Al}_{2} \mathrm{O}_{3} ; 7,00-8,00 \%$ $\mathrm{Fe}_{2} \mathrm{O}_{3} ; 6,50-7,00 \% \mathrm{MgO} ; 4,50-5,20 \% \mathrm{CaO} ; 1,10-1,70 \%$ $\mathrm{Na}_{2} \mathrm{O} ; 6,90-7,90 \% \mathrm{~K}_{2} \mathrm{O} ; 0,50-0,60 \% \mathrm{P}_{2} \mathrm{O}_{5}$. A perda ao fogo situa-se entre $1,0-1,8 \%$ (Tabela 4 ).

Os minettes deste estudo são rochas intermediárias, posicionam-se no diagrama TAS (Figura 9A) no campo do monzonitos e no diagrama $Q^{`}$-ANORM, que apresenta correspondência geoquímica com o diagrama modal QAP, no qual as rochas alocam-se no campo dos sienitos (Figura 9B). Os minettes ocupam área das suítes alcalinas (Figura 9A), o $\mathrm{K}$ é álcalis dominante, e a razão $\mathrm{K}_{2} \mathrm{O} / \mathrm{Na}_{2} \mathrm{O}$ está compreendida entre 4 e 7 (Figura 9C). Esses minettes satisfazem aos critérios de Foley et al. (1987), $\mathrm{MgO}>3 \%, \mathrm{~K}_{2} \mathrm{O}>3 \%$ (Figura 9C) e razão $\mathrm{K}_{2} \mathrm{O} / \mathrm{Na}_{2} \mathrm{O}>3$, para serem classificados como rochas ultrapotássicas (Figura 9D).

Os valores de $\mathrm{MgO}(<7 \%)$ evidenciam que essas rochas se formaram a partir de magmas evoluídos, o que se reflete igualmente nos baixos conteúdos em Ni (85-138 ppm), $\mathrm{Cr}(<100 \mathrm{ppm})$ e Sc $(18-21 \mathrm{ppm})$, e pode indicar fracionamento precoce de olivina e piroxênios.

Os valores dos elementos-traço são relativamente elevados para rochas com média de $55 \%$ de $\mathrm{SiO}_{2}$, como: $\mathrm{Ba}(1.381-1.786 \mathrm{ppm}) ; \mathrm{Rb}(300-332 \mathrm{ppm}) ; \mathrm{Th}(14-$ 20 ppm); Zr (217 - 244 ppm); La (42 - 49 ppm); Pb (14 $20 \mathrm{ppm})$; Hf (6 - $7 \mathrm{ppm})$; e Cs ( $7-10 \mathrm{ppm})$. Esses valores são características apontadas por Rock (1991) como usuais para minettes refletindo a natureza da fonte enriquecida em elementos incompatíveis.

Em diagrama multielementar, normalizado pelo MORB (Figura 10), constata-se que os minettes estudados mostram-se enriquecidos em $\mathrm{Cs}>\mathrm{Rb}>\mathrm{Ba}>\mathrm{K}>\mathrm{Th}>\mathrm{U}>\mathrm{La}>\mathrm{Ce}$, com vales pronunciados em $\mathrm{Nb}$ e $\mathrm{P}$, e um vale suave em $\mathrm{Ti}$. O padrão obtido para o biotita diopsídio cumulato, embora tenha conteúdos mais baixos em todos os elementos em relação aos minettes, exibe um bom paralelismo com aquele dos minettes, o que é interpretado como indicativo de que essas rochas sejam cogenéticas. $O$ cumulato apresenta, ainda, vales em $\mathrm{Ba}, \mathrm{Sr}, \mathrm{P}$ e $\mathrm{Zr}$, que registram o fracionamento de ortoclásio, apatita e zircão.

Os padrões dos Elementos Terras Raras (ETR) das rochas estudadas apresentam fracionamento dos ETRPesados em relação aos ETRLeves e anomalia negativa em európio (Figura 11). Nos minettes, o fracionamento dos $\operatorname{ETR}\left(\mathrm{La}_{\mathrm{N}} / \mathrm{Yb}_{\mathrm{N}}\right)$ situa-se entre 21 e 26, com anomalia negativa em európio $\left(\mathrm{Eu} / \mathrm{Eu}^{*}\right)$ variando de 0,43 a 0,57 . No cumulato, tem-se o fracionamento de ETR $\left(\mathrm{La}_{\mathrm{N}} / \mathrm{Yb}_{\mathrm{N}}\right)$ de 9,46 e a anomalia de 
Tabela 4. Análises químicas para elementos maiores, menores e traços dos minettes e cumulato do Stock Monzonítico Glória Norte. Os elementos W, Sn, Mo, Ag, Cd, Bi e Sb têm concentração inferior ao limite de detecção de 0,1ppm. Hg $<0,01 \mathrm{ppm}, \mathrm{Au}<0,80 \mathrm{ppm}$ e Se $<0,50 \mathrm{ppm}$.

\begin{tabular}{|c|c|c|c|c|c|c|}
\hline$\%$ & FDS-77J & FDS-77G & FDS-77E & FDS-77I & FDS-77C & FDS-3C \\
\hline $\mathrm{SiO}_{2}$ & 53,07 & 55,23 & 55,35 & 55,54 & 55,94 & 56,94 \\
\hline $\mathrm{TiO}_{2}$ & 0,76 & 0,80 & 0,81 & 0,79 & 0,79 & 0,76 \\
\hline $\mathrm{Al}_{2} \mathrm{O}_{3}$ & 12,89 & 12,60 & 12,63 & 12,84 & 12,41 & 12,89 \\
\hline $\mathrm{Fe}_{2} \mathrm{O}_{3}$ & 10,43 & 7,73 & 7,84 & 7,20 & 8,03 & 7,01 \\
\hline $\mathrm{MnO}$ & 0,27 & 0,15 & 0,16 & 0,14 & 0,16 & 0,13 \\
\hline $\mathrm{MgO}$ & 9,26 & 7,04 & 6,81 & 6,96 & 6,59 & 6,63 \\
\hline $\mathrm{CaO}$ & 9,26 & 5,22 & 5,21 & 4,83 & 4,93 & 4,54 \\
\hline $\mathrm{Na}_{2} \mathrm{O}$ & 0,51 & 1,28 & 1,13 & 1,58 & 1,14 & 1,70 \\
\hline $\mathrm{K}_{2} \mathrm{O}$ & 2,37 & 7,66 & 7,91 & 7,19 & 7,63 & 6,96 \\
\hline $\mathrm{P}_{2} \mathrm{O}_{5}$ & 0,08 & 0,65 & 0,63 & 0,62 & 0,58 & 0,59 \\
\hline LOI & 1,60 & 1,10 & 1,00 & 1,80 & 1,30 & 1,30 \\
\hline Total & 100,50 & 99,46 & 99,48 & 99,49 & 99,50 & 99,45 \\
\hline $\mathrm{Ba}(\mathrm{ppm})$ & 117,0 & $1.523,0$ & $1.618,0$ & $1.406,0$ & $1.786,0$ & $1.381,0$ \\
\hline $\mathrm{Rb}$ & 179,7 & 332,8 & 322,1 & 320,8 & 30,4 & 326,6 \\
\hline $\mathrm{Sr}$ & 41,2 & 377,5 & 374,7 & 398,4 & 387,2 & 399,9 \\
\hline Y & 6,7 & 16,2 & 14,1 & 14,0 & 13,8 & 13,0 \\
\hline $\mathrm{Zr}$ & 32,8 & 237,5 & 243,4 & 220,1 & 217,2 & 221,8 \\
\hline $\mathrm{Nb}$ & 2,5 & 6,0 & 5,4 & 6,0 & 5,3 & 6,0 \\
\hline Th & 2,4 & 20,9 & 15,7 & 18,6 & 14,4 & 16,2 \\
\hline $\mathrm{Pb}$ & - & 13,9 & 13,7 & 10,7 & 12,1 & 10,6 \\
\hline $\mathrm{Cu}$ & 31,0 & - & 135,3 & 125,9 & 68,1 & 108,2 \\
\hline $\mathrm{Ni}$ & 72,2 & 105,4 & 106,3 & 114,8 & 85,3 & 116,9 \\
\hline $\mathrm{Cr}$ & 118,0 & 76,1 & 80,3 & 75,8 & 68,9 & 66,6 \\
\hline V & 131,0 & 139,0 & 1340,0 & 134,0 & 144,0 & 129,0 \\
\hline $\mathrm{Hf}$ & 1,6 & 7,0 & 6,5 & 6,4 & 6,2 & 6,7 \\
\hline Cs & 8,0 & 10,2 & 9,1 & 8,5 & 9,0 & 7,9 \\
\hline $\mathrm{Ta}$ & 0,1 & 0,1 & 0,2 & 0,1 & 0,2 & $<0,1$ \\
\hline Co & 53,2 & 27,4 & 27,4 & 28,2 & 27,7 & 29,5 \\
\hline $\mathrm{Zn}$ & 70,0 & 87,0 & 90,0 & 82,0 & 87,0 & 78 \\
\hline $\mathrm{Be}$ & 3,0 & 4,0 & 2,0 & $<1,0$ & 1,0 & 2,0 \\
\hline$U$ & 0,7 & 2,9 & 2,9 & 3,9 & 2,2 & 2,9 \\
\hline Ga & 13,3 & 19,0 & 18,1 & 19,2 & 18,4 & 20,5 \\
\hline Sc & 27,0 & 21,0 & 19,0 & 20,0 & 20,0 & 18,0 \\
\hline $\mathrm{Tl}$ & 12,9 & 1,6 & 1,5 & 1,7 & 1,4 & 1,6 \\
\hline $\mathrm{La}$ & 8,7 & 49,1 & 46,1 & 47,5 & 42,1 & 43,5 \\
\hline $\mathrm{Ce}$ & 19,0 & 95,1 & 83,4 & 91,4 & 79,5 & 89,2 \\
\hline $\operatorname{Pr}$ & 2,81 & 10,21 & 9,02 & 10,08 & 8,87 & 9,86 \\
\hline $\mathrm{Nd}$ & 12,9 & 40,3 & 35,2 & 38,8 & 30,1 & 37,2 \\
\hline Sm & 3,29 & 7,31 & 6,0 & 7,15 & 6,11 & 6,26 \\
\hline Eu & 0,55 & 0,9 & 0,95 & 1,02 & 0,9 & 0,99 \\
\hline $\mathrm{Gd}$ & 2,33 & 5,66 & 4,73 & 5,61 & 4,73 & 4,54 \\
\hline $\mathrm{Tb}$ & 0,29 & 0,71 & 0,59 & 0,63 & 0,59 & 0,62 \\
\hline Dy & 1,48 & 3,24 & 2,88 & 3,38 & 3,0 & 2,78 \\
\hline $\mathrm{Ho}$ & 0,24 & 0,68 & 0,52 & 0,58 & 0,53 & 0,44 \\
\hline Er & 0,61 & 1,79 & 1,58 & 1,28 & 1,27 & 1,18 \\
\hline $\mathrm{Tm}$ & 0,09 & 0,21 & 0,2 & 0,17 & 0,19 & 0,17 \\
\hline $\mathrm{Yb}$ & 0,62 & 1,39 & 1,32 & 1,2 & 1,31 & 1,14 \\
\hline Lu & 0,09 & 0,20 & 0,2 & 0,18 & 0,21 & 0,16 \\
\hline Total ETR & 53,0 & 216,80 & 192,70 & 209,0 & 179,40 & 198,0 \\
\hline
\end{tabular}

LOI: perda ao fogo. 
$\mathrm{Eu} / \mathrm{Eu}^{*}=0,61$. A semelhança entre os padrões dos minettes e do biotita diopsídio cumulato é mais um argumento a favor da hipótese de que essas rochas sejam cogenéticas. Por outro lado, o perfil fracionado dos minettes sugere igualmente que esse magma tenha sido originado por fusão parcial profunda com retenção de granada na fonte.

\section{DISCUSSÃO}

As rochas ultrapotássicas são classificadas por Foley et al. (1987) em quatro grupos distintos. O Grupo I, representado pelos lamproítos, é caracterizado por baixos conteúdos em $\mathrm{CaO}$ e $\mathrm{Al}_{2} \mathrm{O}_{3}$, alta razão $\mathrm{K}_{2} \mathrm{O} / \mathrm{Al}_{2} \mathrm{O}_{3}$, altos valores de \#mg e de elementos incompatíveis; geralmente contém xenólitos mantélicos (e.g. dunito, harzburgito), limita-se a ocorrer associado a outras rochas ultrapotássicas e tem gênese a partir da fusão de manto com altos $\mathrm{H}_{2} \mathrm{O}, \mathrm{F}, \mathrm{CH}_{4}$ e pobre em $\mathrm{CO}_{2}$. O Grupo II, representado pelos kamafugitos, tem baixo
$\mathrm{SiO}_{2}$, alto $\mathrm{CaO}$ e conteúdo de elementos incompatíveis com menor enriquecimento em relação às rochas do Grupo I, exceto pelo alto $\mathrm{Sr}$; tem gênese associada à fusão de manto rico em $\mathrm{CO}_{2}$ e pobre em $\mathrm{H}_{2} \mathrm{O}$. As rochas do Grupo III, representadas pelas lavas potássicas da Província Romana, limitam-se a ocorrer em áreas orogênicas, são rochas com alto $\mathrm{CaO}, \mathrm{Al}_{2} \mathrm{O}_{3}$, baixos conteúdos de $\mathrm{Ti}$, Ta e $\mathrm{Nb}$ explicados pela retenção de fases titanadas no resíduo da fusão, e o baixo valor de \#mg é atribuído à cristalização fracionada de magma oriundo de manto com prévio enriquecimento em elementos incompatíveis. O Grupo IV reúne rochas com características intermediárias entre os três primeiros grupos e é tido como proveniente de magmas ultrapotássicos que sofreram interações diversas com líquidos crustais.

Nos diagramas geoquímicos propostos por Foley et al. (1987) para classificar as rochas ultrapotássicas, constata-se que os minettes do SGN posicionam-se em vários desses diagramas no campo das rochas do Grupo I (Figuras 12A, 12B e 12C), das rochas dos Grupos II e III (Figuras 12D
A

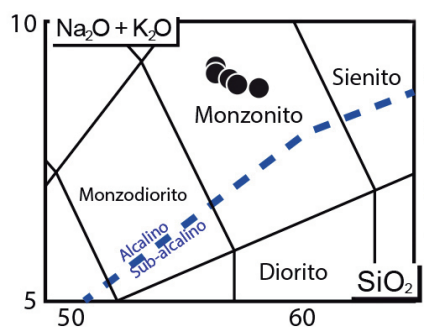

B

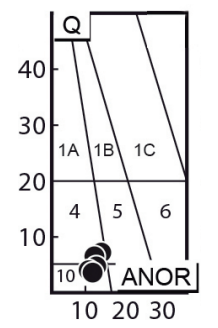

C

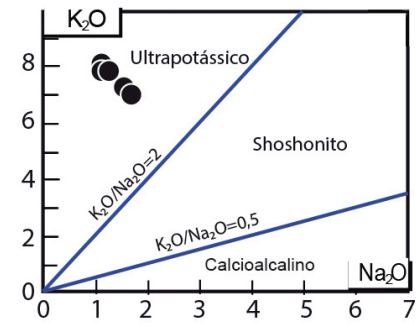

D

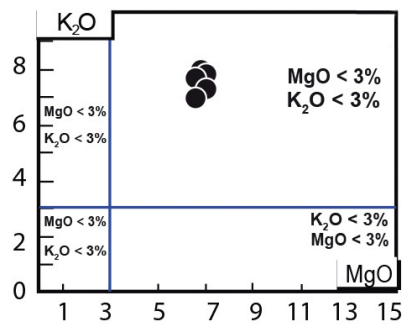

Figura 9. Diagramas geoquímicos aplicados aos minettes do Stock Monzonítico Glória Norte; (A) TAS (total de álcalis versus sílica) com campos de Cox et al. (1979); (B) Q' = [100*Qz/(Qz + Ab + An)] versus ANOR = [100An/(An + Or)] de Streckeisen e Le Maitre (1979); (1A) granito alcalino; (1B) sienogranito; (1C) monzogranito; (4) quartzo sienito alcalino; (5) quartzo sienito; (6) quartzo monzonito; (10) sienito alcalino; (C) $\mathrm{K}_{2} \mathrm{O}$ versus $\mathrm{Na}_{2} \mathrm{O}$ com limites de Turner et al. (1996) para os campos ultrapotássico, shoshonítico e calcioalcalino; (D) $\mathrm{K}_{2} \mathrm{O}$ versus MgO com campos de Conceição et al. (1997).

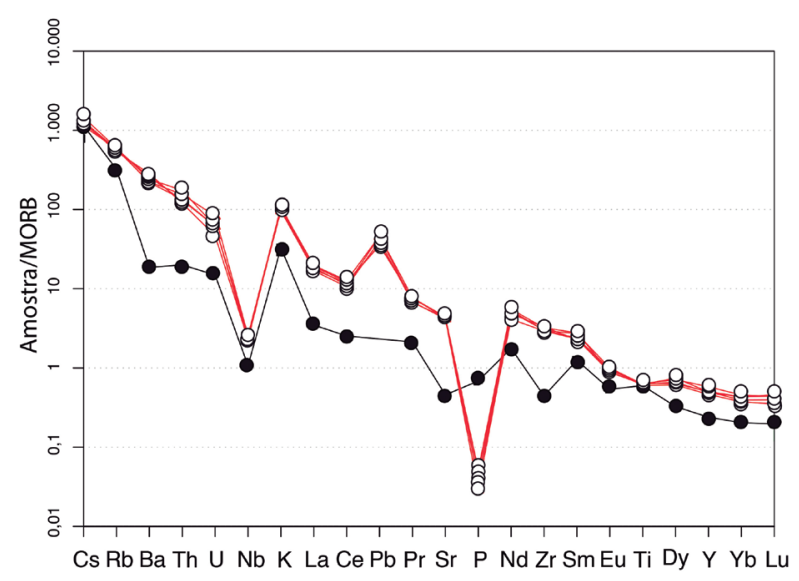

MORB: basaltos de cadeias meso-oceânicas.

Figura 10. Diagrama multielementar normalizado pelo MORB (Sun e McDonough, 1989) aplicado aos minettes e cumulato do Stock Monzonítico Glória Norte.

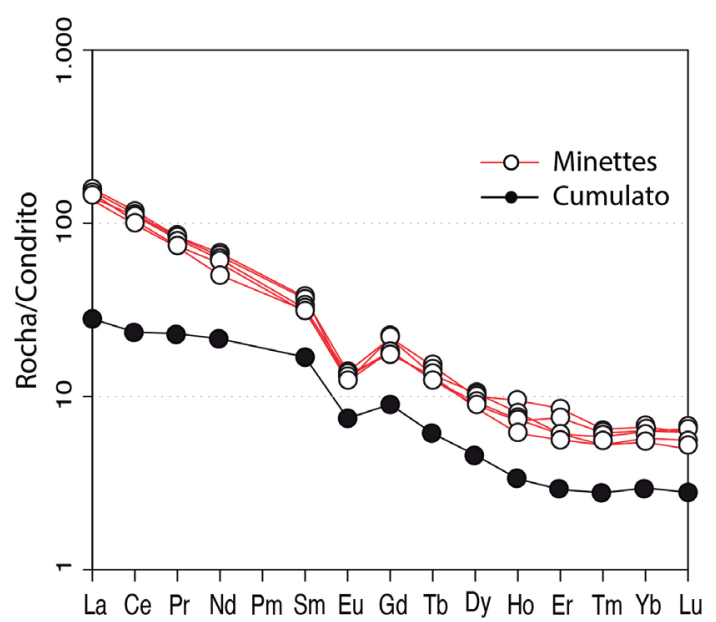

Figura 11. Diagrama com os espectros de Elementos Terras Raras normalizados pelo condrito (Boynton, 1984) aplicado aos minettes e cumulato do Stock Monzonítico Glória Norte. 
e 12E) ou do Grupo IV (Figura 12F). Esse comportamento não é uma particularidade dos minettes do SGN: na literatura, em vários trabalhos sobre minettes, observa-se que eles apresentam esse mesmo posicionamento dúbio nesses diagramas. Esse fato é atribuído por vários autores (e.g., Rock, 1987; Conticelli, 1998; Prelevic et al., 2007; Sandoval, 2016) como devido à contaminação de magmas do Grupo I (lamproíticos) com a crosta continental ou magma traquítico. Nos minettes do SGN, essa feição pode refletir a intensidade da mistura.

Foley et al. (1987) recomendaram que, para refinar os critérios de classificação das rochas ultrapotássicas, deve-se considerar igualmente o conjunto dos elementos-traço. No diagrama multielementar normalizado pelo condrito (Figura 13), observa-se que nas rochas estudadas - minettes e cumulato - os conteúdos de elementos-traço são inferiores à média dos elementos-traço das rochas ultrapotássicas dos grupos I e II (Figura 13). A presença de vales pronunciados em $\mathrm{Nb}$, $\mathrm{Ta}$ e Ti nos padrões das rochas deste estudo - minettes e cumulato - as correlacionam com suítes ultrapotássicas orogênicas (Grupo III).

Em diversos diagramas geoquímicos (Figuras 10, 11 e 13) o biotita diopsídio cumulato apresenta padrão similar àqueles dos minettes, sugerindo que esse cumulato represente
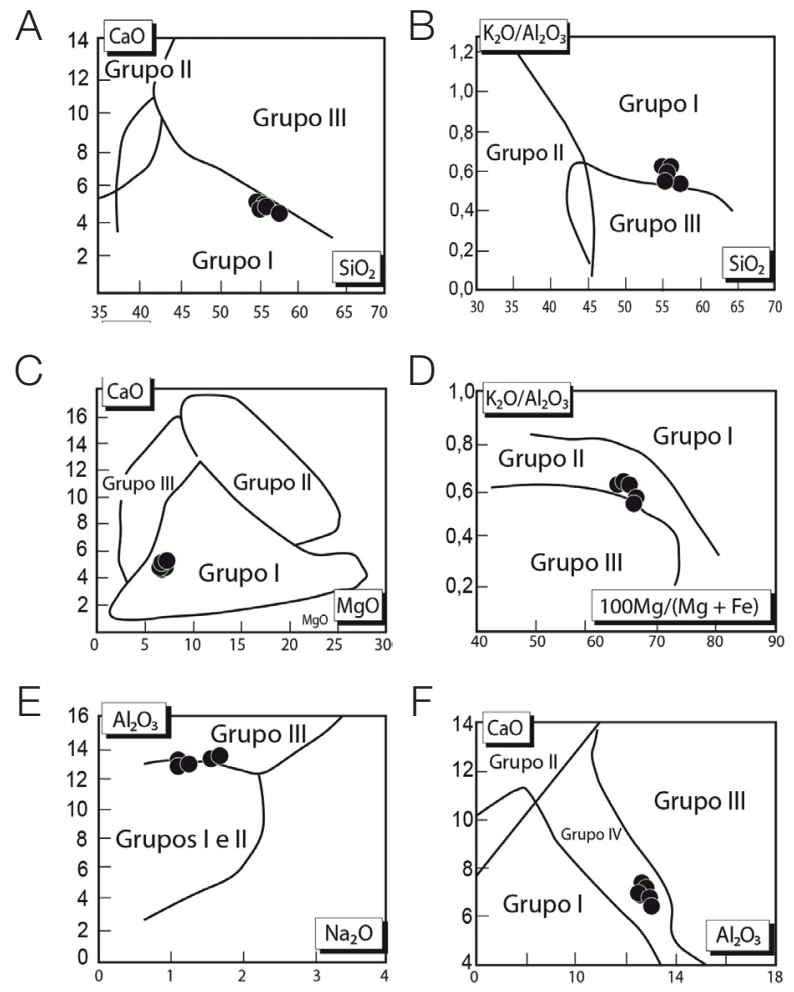

Figura 12. Diagramas para a classificação de rochas ultrapotássicas propostos por Foley et al. (1987) aplicados aos minettes estudados. produto da evolução do magma lamprofírico que cristalizou os minettes estudados.

O conteúdo de elementos-traço dos minettes deste estudo é similar ao dos enclaves máficos microgranulares (Figura 14) presentes no SGS (Conceição et al., 2016), cuja idade de cristalização situa-se a $626 \pm 7 \mathrm{Ma}\left(\mathrm{U}_{-} \mathrm{Pb}_{\text {Zircão }}\right.$ Shrimp - Conceição, no prelo). Os dados geocronológicos disponíveis indicam que, pelo menos, durante aproximadamente $38 \mathrm{Ma}(626$ - $588 \mathrm{Ma})$ magmas ultrapotássicos estiveram presentes no SOS e seguramente contribuíram para a granitogênese neste orógeno, particularmente no Domínio Macururé.

Os valores de elementos-traço apresentados pelos minettes do SGN sugerem que a fonte desse magma seja um manto metassomatizado (Figura 14), similar ao considerado na gênese de lamprófiros em diversas regiões (e.g., Foley et al., 1987; Rogers et al., 1992; Müller et al., 1992; Conceição, 1992; Conceição et al., 1997; Miller et al., 1999; Liu et al., 2014; Cheng e Guo, 2017). Magmas potássicos e ultrapotássicos saturados $\mathrm{em} \mathrm{SiO}_{2}$ podem, segundo Müller et al. (1992), estar presentes em vários ambientes geodinâmicos (e.g., intraplaca, arcos de ilha, margens continentais ativas e em áreas pós-colisionais). O processo responsável pelo metassomatismo no manto é o aporte de fluidos provenientes da litosfera oceânica subductada (sedimentos e basaltos alterados) tornando o manto essencialmente clinopiroxenítico e com mineralogia exótica constituída de apatita, flogopita, clinopiroxênio e K-pargasita.

A ambiência pós-colisional do SGN pode indicar que o processo de formação dos magmas ultrapotássicos no Domínio Macururé reflete a quebra de placa oceânica subductada, como sugerido por Sacks e Secor (1990) e

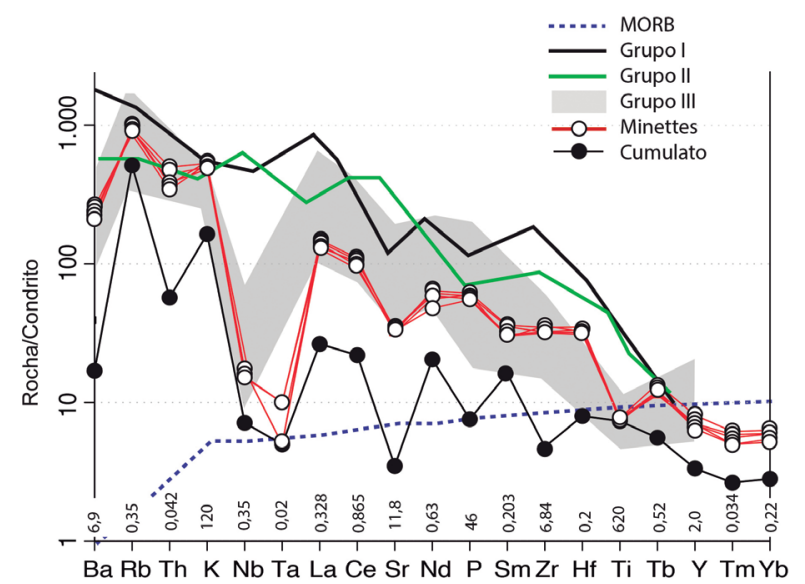

Figura 13. Diagrama multielementar normalizado pelo condrito de Thompson (1982) aplicado a minettes e cumulatos do Stock Monzonítico Glória Norte. Padrões representando composição média dos grupos de rochas ultrapotássicas de Foley et al. (1987) e padrão para o MORB (basaltos de cadeias meso-oceânicas) (Sun, 1980). 
Davies e Blanckenburg (1995), com a ascensão da astenosfera quente provocando fusão parcial do manto litosférico previamente metassomatizado.

\section{CONCLUSÕES}

Os dados obtidos neste estudo permitem propor que os minettes estudados são produtos da cristalização de magma ultrapotássico contemporâneo à intrusão do magma latítico responsável pela cristalização, a $588 \mathrm{Ma}$, dos monzonitos do Stock Glória Norte. A ausência de deformação nessas rochas suporta a hipótese de Lisboa (2014), de que o SGN representa a última expressão magmática do SOS.

A granulação fina nos minettes e a presença de cristais esqueléticos (e.g., apatita, biotita, diopsídio e minerais opacos) indicam taxa de cristalização rápida dos lamprófiros, que deve ter preservado o magma lamprofírico de interação importante com os monzonitos encaixantes. As zonações composicionais identificadas em cristais de plagioclásio, clinopiroxênio e feldspato alcalino refletem igualmente os efeitos das instabilidades térmicas ocorridas durante a

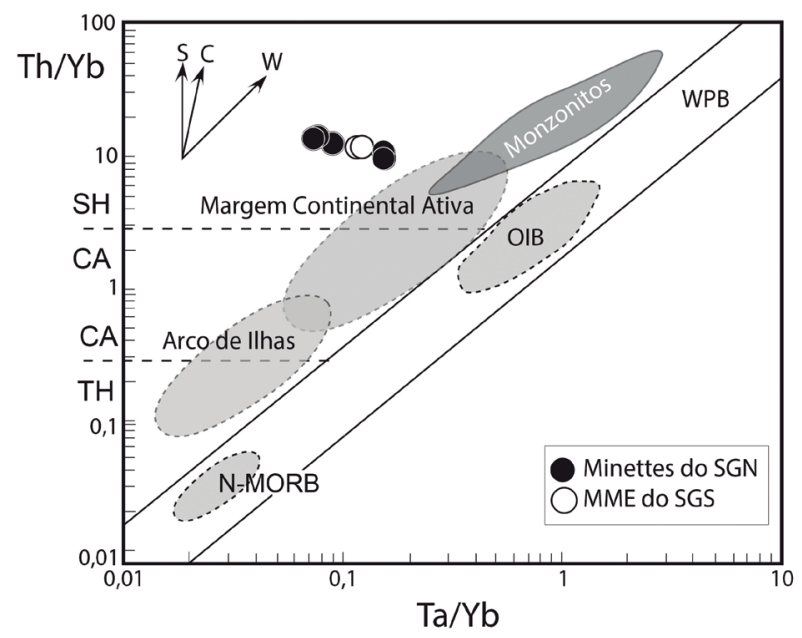

Sh: shoshonito; CA: calcioalcalino; TH: tholeiíto; OIB: basaltos de ilhas oceânicas; WPB: basaltos intraplaca; N-MORB: basaltos de cadeias mesooceânicas normais; SGN: Stock Monzonítico Glória Norte; MME: enclaves máficos microgranulares; SGS: Stock Glória Sul.

Figura 14. Diagrama $\mathrm{Ta} / \mathrm{Yb}$ versus $\mathrm{Th} / \mathrm{Yb}$ de Menzies e Kyle (1990) aplicado aos minettes do Stock Monzonítico Glória Norte. As delimitações dos campos de N-MORB, OIB, Arco de llhas, Margem Continental Ativa e WPG são segundo Menzies e Kyle (1990). Componentes dos vetores de enriquecimento devido (S) à zona de subducção, (C) à contaminação crustal e (W) ao enriquecimento intraplaca são de Nédli e Tóth (2007); a área indicada corresponde aos monzonitos do Stock Glória Norte (Lisboa, 2014); o círculo preto, aos minettes do Stock Monzonítico Glória Norte deste trabalho; e os círculos brancos, aos enclaves microgranulares do Stock Glória Sul após Conceição et al. (2016). cristalização dessas rochas. A homogeneidade composicional encontrada nos diferentes enclaves de minettes na região da Pedreira do Didi sugere que as amostras obtidas representem a composição do magma ultrapotássico que foi intrusivo na câmara magmática Glória Norte.

A presença de borda de biotita e de anfibólio entre os enclaves biotita diopsídio cumulato e o monzonito encaixante refletem o desequilíbrio geoquímico entre eles. Por outro lado, a ausência de bordas similares entre esses cumulatos e os minettes é considerada como a existência de equilíbrio geoquímico entre essas rochas. A mesma composição química observada entre os cristais de clinopiroxênio (augita-diopsídio) dos minettes e cumulato sugere que os cumulatos representem produtos da cristalização do magma lamprofírico.

Os dados geoquímicos evidenciaram que os minettes correspondem a rochas ultrapotássicas, classificadas como do Grupo III, que são magmas de ambientes orogênicos, caracterizados por empobrecimento em $\mathrm{Nb}, \mathrm{Ta}$ e Ti. As relações entre elementos-traço (e.g., $\mathrm{Th} / \mathrm{Yb}, \mathrm{Ta} / \mathrm{Yb}$ ) indicam que esses magmas apresentam assinatura de ambiente de arco vulcânico. Todavia, a ausência da deformação regional nessas rochas é compatível com posicionamento tectônico pós-colisional.

Magmas capazes de cristalizar rochas como os minettes estudados são atribuídos pela literatura como formados em período posterior a eventos colisionais, tendo como fonte a fusão parcial de manto previamente metassomatizado.

Por fim, a presença de magmas ultrapotássicos do Grupo III capazes de cristalizar minettes no SOS revela que no final desta orogênese neoproterozoica magmas básicos e intermediários foram contemporâneos à colocação de magmatismo granítico. E que, provavelmente, esses magmas tiveram papel importante na formação da granitogênese nesse período.

\section{AGRADECIMENTOS}

Os autores agradecem ao suporte financeiro do Conselho Nacional de Desenvolvimento Científico e Tecnológico (CNPq) e à Fundação de Apoio à Pesquisa e à Inovação Tecnológica do Estado de Sergipe (FAPITEC), processos números 308059/2014-0 (CNPq-PQ), 308059/2014-0 (CNPq-PQ), 473013/2012-4 (CNPq-Universal), 405387/2016-4 (CNPqUniversal) e 019.203.02538/2009-7 (Pronex/Fapitec/CNPq). Milena Prado Fontes é bolsista de mestrado FAPITEC do Programa de Pós-Graduação em Geociências e Análise de Bacias da UFS. Externamos nossos agradecimentos às Dras. Cristina Maria Burgos Carvalho e Rita Cunha Leal Menezes, pesquisadoras da Superintendência de Salvador da CPRM, pelas discussões e a confecção das lâminas delgado-polidas. Aos revisores deste texto expressamos igualmente nossos agradecimentos. 


\section{REFERÊNCIAS}

Barbarin, B., Didier, J. (1991). Macroscopic features of mafic microgranular enclaves. In: J. Didier, B. Barbarin (Eds.), Enclaves and Granite Petrology: developments in petrology (v. 13, 253-261). New York: Elsevier Science.

Bédard, J. H. (1994). Mesozoic east North American alkaline magmatismo. Parte 1. Evolution of Manteregian lamprophyres, Québec, Canada. Geochimica et Cosmochimica Acta, 58(1), 95-112. DOI: 10.1016/0016-7037(94)90449-9.

Boynton, W. V. (1984). Cosmochemistry of the rare earth elements: meteorite studies. In: P. Henderson (Ed.), Rare Earth Element Geochemistry (63-114). Amsterdã: Elsevier.

Brito Neves, B. B., Sial, A. N., Beurlen, H. (1977). O sistema de dobramento Sergipana-Análise do conhecimento. Reunião Preparatória para o Simpósio Cráton São Francisco e Faixas Marginais, 3, 369-391. Salvador: SBG.

Bueno, J. F., Oliveira, E. P., McNaughton, N., Laux, J. H. (2009). U-Pb dating of granites in the Neoproterozoic Sergipano Belt, NE-Brazil, and implications for the timing and duration of continental collision. Gondwana Research, 15, 86-97. DOI: 10.1016/j.gr.2008.06.003.

Carlier, G., Lorand, J.-P., Audebaud, E., Kienast, J.-R. (1997). Petrology of an unusual orthopyroxenebearing minette suite from southeastern Peru, eastern Andean Cordillera: Al-rich lamproitos contaminated by peraluminous granites. Journal of Volcanology and Geothermal Research, 75(1-2), 59-87. DOI: 10.1016/ S0377-0273(96)00035-2.

Caroff, M., Labry, C., Gall, B. L., Authemayou, C., Grosjean, D. B., Guillong, M. (2015). Petrogenesis of late-Variscan high-K alkali-calcic granitoids and calc-alkalic lamprophyres: The Aber-Ildut/North-Ouessant complex, Armorican massif, France. Lithos, 238, 140-155. DOI: 10.1016/j. lithos.2015.09.025.

Cheng, Z., Guo, Z. (2017). Post-collisional ultrapotassic rocks and mantle xenoliths in the Sailipu volcanic filed of Lhasa terrane, south Tibet: Petrological and geochemical constraints on mantle source and geodynamic setting. Gondwana Research, 46, 17-42. DOI: 10.1016/j. gr.2017.02.008.

Conceição, H. (1992). Petrology of the Syenites from the Salvador-Curaçá Mobile belt (Bahia-Brazil): Geodynamic Significance. Anais da Academia Brasileira de Ciências, 65(Supl.1), 17-32.
Conceição, H., Oliveira, O. M. C., Martin, H., Rosa, M. L. S., Conceição, R. V., Plá Cid, J. (1997). Petrologia do magmatismo alcalino potássico com afinidade lamprofírica e assinatura de subducção no sul do Estado da Bahia: Maciço Sienítico Anuri. Geochimica Brasiliensis, 11(2), 171-186.

Conceição, H., Rios, D. C., Rosa, M. L. S. (1995). Petrologia da associação sienito-lamprófiro: caso da intrusão Morro do Afonso (Greenstone Belt Rio Itapicuru, Bahia). Geochimica Brasiliensis, 9(1), 91-109.

Conceicão, J. A. (2018). Geoquímica e Geocronologia dos Leucogranitos do Domínio Macururé, Sistema Orogênico Sergipano. Tese (Doutorado). Salvador: Programa de PósGraduação em Geologia - UFBA. (No prelo).

Conceição, J. A., Rosa, M. L. S., Conceição, H. (2016). Sienogranitos leucocráticos do Domínio Macururé, Sistema Orogênico Sergipano, Nordeste do Brasil: Stock Glória Sul. Brazilian Journal of Geology, 46(1), 63-77. DOI: 10.1590/2317-4889201620150044.

Conticelli, S. (1998). The effect of crustal contamination on ultrapotassic magmas with lamproitic affinity: mineralogical, geochemical and isotope data from the Torre Alfina lavas and xenoliths, Central Italy. Chemical Geology, 149(1-2), 51-81. DOI: 10.1016/S0009-2541(98)00038-2.

Cox, K. G., Bell, J. D., Pankhurst, R. J. (1979). The interpretation of igneous rocks. Boston, George Allen and Unwin London: Springer.

D’el-Rey Silva, L. J. H. (1999). Basin infilling in the southerncentral part of the Sergipano Belt (NE Brazil) and implications for the evolution of Pan-African/Brasiliano cratons and Neoproterozoic cover. Journal of South American Earth Sciences, 12(5), 453-470. DOI: 10.1016/S0895-9811(99)00034-6.

Davies, J. H., Blanckenburg, F. (1995). Slab breakoff - a model of lithosphere detachment and its test in the magmatism and deformation of collisional orogens. Earth and Planetary Science Letters, 129(1-4), 85-102. DOI:10.1016/0012-821X(94)00237-S.

Davison, I., Santos, R. A. (1989). Tectonic Evolution of the Sergipano Fold Belt, NE Brazil, during the Brasiliano Orogeny. Precambrian Research, 45(4), 319-342. DOI: 10.1016/0301-9268(89)90068-5.

Foley, S. F., Venturelli, G., Green, D. H., Toscani, L. (1987). The Ultrapotassic Rocks: Characteristics, classification, and constraints for petrogenetic models. Earth-Science Reviews, 24(2), 81-134. DOI: 10.1016/0012-8252(87)90001-8. 
Humphrey, F. L., Allard, G. O. (1962). Reconnaissance geology of pre-cretaceous rocks in the state of Sergipe. Rel. 230, Div. Reg. de Exploração, RPNE/PETROBRAS. Maceió: PETROBRAS.

Le Maître, R. W., Bateman, P., Dubek, A., Keller, J., Lameyre, J., Le Bas, M. J., Sabine, P. A., Schmidt, R., Sorensen, H., Streckeisen, A., Wooley, A. R., Zanettin, B. (1989). In: R. W. Le Maître (Ed.). (2002). A Classification of Igneous Rocks and Glossary of Terms: Recommendations of the International Union of Geological Sciences Subcommission on the Systematics of Igneous Rocks. Londres: Blackwell.

Lisboa, V. A. C. (2014). Petrologia e geocronologia do Maciço Glória Norte, Faixa de Dobramentos Sergipana, NE do Brasil. Dissertação (Mestrado). São Cristóvão: Programa de Pós-Graduação em Geociências de Análise de Bacias - UFS.

Liu, D., Zhao, Z., Zhu, D.-C., Niu, Y., DePaolo, D. J., Harrison, T. M., Mo, X., Dong, G., Zhou, S., Sun, C., Zhang, Z., Liu, J. (2014). Postcollisional potassic and ultrapotassic rocks in southern Tibet: mantle and crustal origins in response to India-Asia collision and convergence. Geochimica Cosmochimica, 143, 207-231. DOI: 10.1016/j. gca.2014.03.031.

Lobo, A. F. B. (2016). Petrografia e Mineraloquímica das Rochas Cálcio-Silicáticas do Domínio Macururé, Sistema Orogênico Sergipano. Monografia (Graduação). São Cristóvão: Departamento de Geologia - UFS.

Mendonça, L. H. (2016). Contribuição a petrologia de stocks graníticos nos municípios de Canhoba e Aquidabã, NE do Sistema Orogênico Sergipano. Dissertação (Mestrado), São Cristóvão: Programa de Pós-Graduação em Geociências de Análise de Bacias -UFS.

Menzies, M. A., Kyle, P. R. (1990). Continental volcanism: a crust-mantle proble. In: M. A. Menzies (Ed.), Continental Mantle (157-177). Oxford: Oxford Science Publications; Claredon Press, Oxford.

Miller, C., Schuster, R., Klötzli, U., Frank, W., Purtscheller, F. (1999). Post-collisional potassic and ultrapotassic magmatism in SW Tibet: geochemical and $\mathrm{Sr}-\mathrm{Nd}-\mathrm{Pb}-\mathrm{O}$ isotopic constraints for mantle source characteristics and petrogenesis. Journal of Petrology, 40(9), 1399-1424. DOI: 10.1093/ petroj/40.9.1399.

Morimoto, N. (1989). Nomenclature of pyroxenes. Canadian Mineralogist, 27, 143-156.
Müller, D., Rock, N. M. S., Groves, D. I. (1992). Geochemical discrimination between shoshonitic and potassic volcanic rocks from different tectonic settings: a pilot study. Mineralogy and Petrolology, 46(4), 259-289. DOI: 10.1007/BF01173568.

Murphy, M. A., Salvador, A. (1999). International Stratigraphic Guide - an abridged version. Episodes, 22(4),225-271.

Nédli,Z., Tóth, T. M. (2007). Origin and geodynamic significance of Upper Cretaceous lamprophyres from the Villány Mts ( $\mathrm{S}$ Hungary). Mineralogy and Petrology, 90(1-2), 73-107.

Oliveira, E. P., Bueno, J. F., McNaughton, N. J., Silva Filho, A. F., Nascimento, R. S., Donatti-Filho, J. P. (2015). Age, composition, and source of continental arc- and syncollision granites of the Neoproterozoic Sergipano Belt, Southern Borborema Province, Brazil. Journal of South American Earth Sciences, 58, 257-280. DOI: 10.1016/j. jsames.2014.08.003.

Plá Cid, J., Campos, C. S., Nardi, L. V. S., Florisbal, L. (2012). Petrology of Gameleira Potassic Lamprophyres, São Francisco Craton. Anais da Academia Brasileira de Ciências, 84(2), 377-398. DOI: 10.1590/S0001-37652012005000030.

Paim, M. M., Plá Cid, J., Rosa, M. L. S., Conceição, H., Nardi, L. V. S. (2002). Mineralogy of Lamprophyres and Mafic Enclaves Associated with the Paleoproterozoic Cara Suja Syenite, Northeast Brazil. International Geology Review, 44(11), 1017-1036. DOI: 10.2747/0020-6814.44.11.1017.

Prelevic, D., Foley, S. F., Cvetkovic, V. (2007). A review of petrogenesis of Mediterranean tertiary lamproites: a perspective from the Serbian ultrapotassic province. Geological Society of America, 418, 113-129. DOI: 10.1130/2007.2418(06).

Prelevic, D., Foley, S. F., Cvetkovic, V., Romer, R. L. (2004). Origin of minette by mixing of lamproite and a dacite magmas in Veliki Majdanm Serbia. Journal of Petrology, 45(4), 759792. DOI: $10.1093 /$ petrology/egg 109.

Rock, N. M. S. (1987). The nature and origin of lamprophyres: an overview. In: J. G. Fitton, B. G. J. Upton (Eds.), Alkaline Igneous Rocks (v. 30, 191-226). Londres: Sociedade Geológica de Londres.

Rock, N. M. S. (1991). Lamprohpyres. Glasgow: Blackie.

Rogers, N. W., Hawkesworth, C. J., Palacz, Z. A. (1992). Phlogopite in the generation of olivine melilitites from Namaqualand, South Africa, and implications for element fractionation processes in the upper mantle. Lithos, 28(3-6), 347-365. DOI: 10.1016/0024-4937(92)90014-P. 
Sacks, P. E., Secor, D. T. Jr. (1990). Delamination in collisional orogens. Geology, 18(10), 999-1002. DOI: https://doi. org/10.1130/0091-7613(1990)018<0999:DICO >2.3.CO;2.

Sandoval, S. A. R. (2016). Caraterização petrográfica, geoquímica e isotópica do sienito de Uruana e suas implicações sobre a gênese do magmatismo sin-tectônico da Faixa Brasília. Dissertação (Mestrado). Brasília: Instituto de Geociência-UnB.

Santos, L. R. (2016). Petrologia do Stock Canindé Velho, Sistema Orogênico Sergipano, NE do Brasil. Dissertação (Mestrado). São Cristóvão: Programa de Pós-Graduação em Geociências de Análise de Bacias - UFS.

Santos, R. A., Martins, A. A., Neves, J. P., Leal, R. A. (2001). Geologia e Recursos Minerais do Estado de Sergipe. Texto Explicativo do Mapa Geológico do Estado de Sergipe. Mapa color. Escala 1:250.000. Convênio CPRM-Codise. Brasília: CPRM.

Santos, R. A., Menezes, F., Dalton de Souza, N. R., Teixeira, L. R., Motta, A. C., Leal, R. A., Braz Filho, P. A. (1988). Geologia da Região Nordeste. Folhas Carira (SC. $24-Z-A-I I I) e$ Jeremoabo (SC. 24-Z-A-II). Estados da Bahia e Sergipe. Relatório Final. Convênio DNPM/CPRM. Brasília; CPRM. 8 v.

Silva Filho, M. A., Bomfim, L. F. C., Santos, R. A., Santana, A. C., Braz Filho, P. A., Leal R. A. (1979). Geologia da geossinclinal sergipana e do seu embasamento: Projeto Baixo São Francisco/Vaza Barris. Brasília: DNPM.

Soares, H. S. (2016). Stocks Santa Maria e Monte Pedral, Magmatismo Tipo Serra do Catu, no Domínio Canindé, Sergipe: contribuição à geologia, petrografia e geoquímica. Monografia (Graduação). São Cristóvão: Departamento de Geologia-UFS.

Streckeisen,A.(1976). To each plutonic rock its propername. EarthScienceReviews, 12(1), 1-33.DOI: 10.1016/0012-8252(76)90052-0.
Streckeisen, A. L., Le Maitre, R. W. (1979). Chemical approximation to modal QAPF classification of the igneous rocks. Neus Jahrbuch fur Mineralogie, 136, 169-206.

Sun, S. S. (1980). Lead isotopic study of young volcanic rocks from mid-ocean ridges, ocean islands and island arcs. Philosophical Transactions of the Royal Society of London, A 297(1431), 409-445. DOI: 10.1098/rsta.1980.0224.

Sun, S. S., McDonough, W. F. (1989). Chemical and isotopic systematics of oceanic basalts; implications for mantle composition and processes. In: A. D. Sanders, M. J. Norry (Eds.), Magmatism in the ocean basins (v. 42, 313-345). Londres: Sociedade Geológica de Londres.

Teixeira, L. R. (2014). Mapa Geológico do Estado de Sergipe. Escala 1:250.000. Salvador: Superintendência de Salvador do Serviço Geológico do Brasil (CPRM) e Companhia de Desenvolvimento Econômico do Estado de Sergipe (CODISE).

Thompson, R. N. (1982). Magmatism of the British Tertiary volcanic Province. Scottish Journal of Geology, 18, 49-107. DOI: $10.1144 /$ sjg18010049.

Turner, S., Arnaud, N., Liu, J., Rogers, N., Hawkesworth, C., Harris, N., Kelley, S., Van Calsteren, V., Deng, W. (1996). Post-collision shoshonitic volcanism on the Tibetan plateau: implications for convective thinning of the lithospheres and the source of ocean island basalts. Journal of Petrology, 37(1), 45-71. DOI: 10.1093/petrology/37.1.45.

Woolley, A. R., Bergman, S. C., Edgar, A. D., Le Bas, M. J., Mitchell, R. H., Rock, N. M. S., Smith, B. H. S. (1996). Classification of lamprophyres, lamproites, kimberlites, and the kalsilitic, melilitic, and leucitic rocks. The Canadian Mineralogist, 34(2), 175-186. 